\title{
Spatial analysis of temperature time series over the Upper Indus Basin (UIB) Pakistan
}

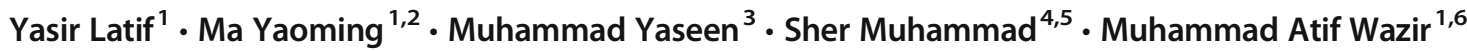

Received: 1 September 2018 / Accepted: 30 August 2019 / Published online: 12 October 2019

(C) The Author(s) 2019

\begin{abstract}
Runoff generated from the Upper Indus Basin (UIB) mainly originates in the massifs of the Hindukush-Karakoram-Himalaya (HKH) region of Pakistan. Water supply in early spring depends upon the snow accumulation in the winter and the subsequent temperature. Seasonal temperature variations corroborate the contemporary dynamics of snow and glaciers. Recently, there has been increasing evidence of accelerated warming in high mountain areas, termed as elevation-dependent warming (EDW). We have identified trends, analyzed inconsistencies, and calculated changes in the maximum, minimum, mean and diurnal temperature range ( $T_{\max }, T_{\min }, T_{\text {mean }}$, and DTR) at 20 weather stations during four-time series: 1961-2013 (first), 1971-2013 (second), 1981-2013 (third), and 1991-2013 (fourth). We employed the Mann-Kendall test to determine the existence of a trend and Sen's method for the estimation of prevailing trends, whereas homogeneity analysis was applied before trend identification using three different tests. This study revealed that the largest and smallest magnitudes of trends appeared in the winter and summer, respectively, particularly during the fourth data series. $T_{\max }$ revealed robust warming at ten stations, most remarkably at Gupis, Khunjrab, and Naltar at rates of $0.29,0.36$, and $0.43{ }^{\circ} \mathrm{C} /$ decade, respectively, during the fourth series. We observed that $T_{\min }$ exhibits a mixed pattern of warming and cooling during the second and third series, but cooling becomes stronger during the fourth series, exhibiting significant trends at twelve stations. Khunjrab and Naltar showed steady warming during the fourth series (spring), at rates of 0.26 and $0.13{ }^{\circ} \mathrm{C} /$ decade in terms of $T_{\text {mean. }}$. The observed decreases in DTR appeared stronger in the fourth series during the summer. These findings tend to partially support the notion of EDW but validate the dominance of cooling spatially and temporally.
\end{abstract}

\section{Introduction}

The High Mountain Asia (HMA) region is mainly classified into three ranges: the combined Hindukush-Karakoram-

Yasir Latif

yasirlatif@itpcas.ac.cn

1 Key Laboratory of Tibetan Environment Changes and Land Surface Processes, Institute of Tibetan Plateau Research, Chinese Academy of Sciences, Beijing 100101, China

2 CAS Center for Excellence in Tibetan Plateau Earth Sciences, Chinese Academy of Sciences, Beijing 100101, China

3 Centre of Excellence in Water Resources Engineering, University of Engineering and Technology Lahore, Lahore, Pakistan

4 Institute of International Rivers and Eco-Security, Yunnan University, Kunming 650500, China

5 International Centre for Integrated Mountain Development, GPO Box 3226, Khumaltar, Kathmandu, Nepal

6 Pakistan Meteorological Department (PMD), Islamabad, Pakistan
Himalaya (HKH), commonly known as the "third pole" (TP) due to the massive volume of glacier cover in its high-altitude basins (Yao et al. 2012). The glacier coverage of HMA provides a huge contribution to riverflow as water supply for millions of people (Immerzeel 2008; Lutz et al. 2016). The snow-capped peaks, glaciers, and resulting water resources originating from this region comprise the Upper Indus Basin (UIB) in Pakistan, which entails a decisive significance to the interests of this country. The Indus River and its tributaries supply the irrigation system, domestic consumption, and hydropower electricity generation to meet the agricultural and economic demands. South and Southeast Asian rivers are dependent on summer monsoons, while the UIB is reliant upon runoff generated from snow and glaciers (Hasson et al. 2014). The riverflow generated within this region contributes to approximately $80 \%$ of the total annual surface water availability of Pakistan, mainly during the summer (June-September) (Ali et al. 2009). Temperature, being the most sensitive parameter, dictates the amount of runoff generated due to either snow or glacier melt particularly in high-altitude regions. The 
Himalayan mountains have featured increased temperatures at the rate of $0.74{ }^{\circ} \mathrm{C}$ over the last century, which is more than the global average temperature increase (IPCC 2007, 2013). The warming of $1.5{ }^{\circ} \mathrm{C}$ at a global scale will result in a $2.1{ }^{\circ} \mathrm{C}$ increase within the HMA (Kraaijenbrink et al. 2017).

The rate of change of temperature and increased greenhouse gasses are proportional to each other at high latitudes, which is a common phenomenon. Recently, evidence of increased rates of warming with increased elevation is growing, and high mountains are more sensitive to temperature change than are low regions due to increased storage of water as snow or ice (Miller et al. 2012; Pepin et al. 2015). This phenomenon is called "elevation-dependent warming" (EDW). Previous studies have documented a warming intensification globally, especially in mountainous regions (Pepin and Siedal 2005, Rangwala et al. 2010). The possible warming is attributed to changes in cloud aggregates (Duan and $\mathrm{Wu} 2006$ ), radiative forcing related to greenhouse gasses (Rangwala et al. 2013), surface albedo feedback (Pepin et al. 2015), and surface heat loss and aerosols (Kraaijenbrink et al. 2017).

A significant number of studies have been comprehensively carried out over the UIB regarding climate change impacts on streamflows and mass balance. Increasing trends in annual, summer and winter precipitation (Archer and Fowler 2004) were reported during (1961-1999). They found significant warming and cooling in the winter and summer, respectively, within the UIB during a similar data interval (Fowler and Archer 2006). During the monsoon season, some researchers have found significant cooling trends, with warming during the pre-monsoon (Sheikh et al. 2009). Similar trends of warming during the winter while cooling in the summer were observed by Khattak et al. (2011), but precipitation patterns remained insignificant between 1967 and 2011. However, these studies were based on old datasets and restricted to specific regions. Some authors, such as Bocchiola and Diolaiuti (2013), have concluded exaggerated warming during the winter and cooling during the summer at Gilgit and Bunji. These authors also noted wetting (insignificant) over Chitral and neighboring north-west Karakoram region, though a drying pattern was observed within the entire UIB. Some recent studies have found warming during the pre-monsoon season rather than during the winter. Latif et al. (2016) found the dominance of significant decreasing precipitation trends spatially and temporally within the UIB.

According to recent studies, eastern and central glaciers experience retreat and present a negative mass balance (Bolch et al. 2012). The negative mass balance and rapid glacier retreat are consistent with global warming. Conversely, positive mass balance and advancing glaciers have been reported during the last decade in the Karakoram (Hewitt 2005). This general stability and advancement of glaciers proposed by Hewitt (2005) is called the Karakoram Anomaly, later dubbed the western Kunlun Shan and
Karakoram Anomaly, as endorsed by (Kääb et al. 2015). These conflicting signals are linked with negative trends in maximum and minimum temperature and increasing precipitation. The rate of warming is directly proportional to the elevation as EDW has been introduced globally and especially over the Tibetan Plateau region (Rangwala et al. 2010). Thus, a comprehensive analysis of recent temperature trends is required to understand these occurrences over the UIB. The present study enables the trend identification by the MannKendall (MK) test of temperature time series data. The core objective involves an evaluation of current elevationdependent warming/cooling trends within the UIB in light of recent data collected at high altitudes between 1995 and 2013 and at low-elevation climatic stations between 1961 and 2013. This study deals with trend detection in annual maximum, minimum, mean, and diurnal temperatures within the UIB.

\section{Study area}

The twenty selected climatic stations within the UIB, including lower- and higher-altitude gauges, were carefully chosen in order to examine temperature variations. This region features a large climatic and topographic variation, including a complex terrain (HKH) encompassing discrete topographical landscapes and conflicting signals of climate change (Archer 2003; Cheema and Bastiaanssen 2012). The UIB covers an extent of $33^{\circ}, 40^{\prime}$ to $37^{\circ}, 12^{\prime} \mathrm{N}$ and $70^{\circ}, 30^{\prime}$ to $77^{\circ}, 30^{\prime} \mathrm{E}$, crossing national borders. This basin shares its border in the east, west, and north with India, China, and Afghanistan, respectively. The total area under the transboundary basin stretches to 1.12 million $\mathrm{km}^{2}$ contributing $47 \%, 39 \%, 8 \%$, and $15 \%$, respectively, to Pakistan, India, China, and Afghanistan (Aquastat 2011). We marked the boundary of this watershed at the conjunction of the Indus River and Kabul from the Digital Elevation Model (DEM) covering all the selected twenty climatic stations for the present study (Fig. 1). The selected stations range from the lowest station at $254 \mathrm{~m}$ (Peshawar) to the highest station at $4400 \mathrm{~m}$ (Khunjrab) solely within Pakistan's political boundaries. The stations within this basin encompassed in India and China are not included due to inaccessible data and different hydrology. Although this study was funded by the Chinese Government, the exclusion of the Chinese portion was carried out intentionally due to the several reasons including the minor contribution to the basin and different hydrology and climate of the Tibetan Plateau. The Tibetan Plateau features warming and rapidly retreating (Wang et al. 2008) and collapsing glaciers such as the Aru Glacier in Tibet (Tian et al. 2017a, b), though this was attributed to a surge such as instability rather than to warming (Kääb et al. 2018), while the Karakoram region exhibits an anomalous behavior of stability and mass gain of glaciers (Gardelle et al. 2012; Minora et al. 2016). All of the 


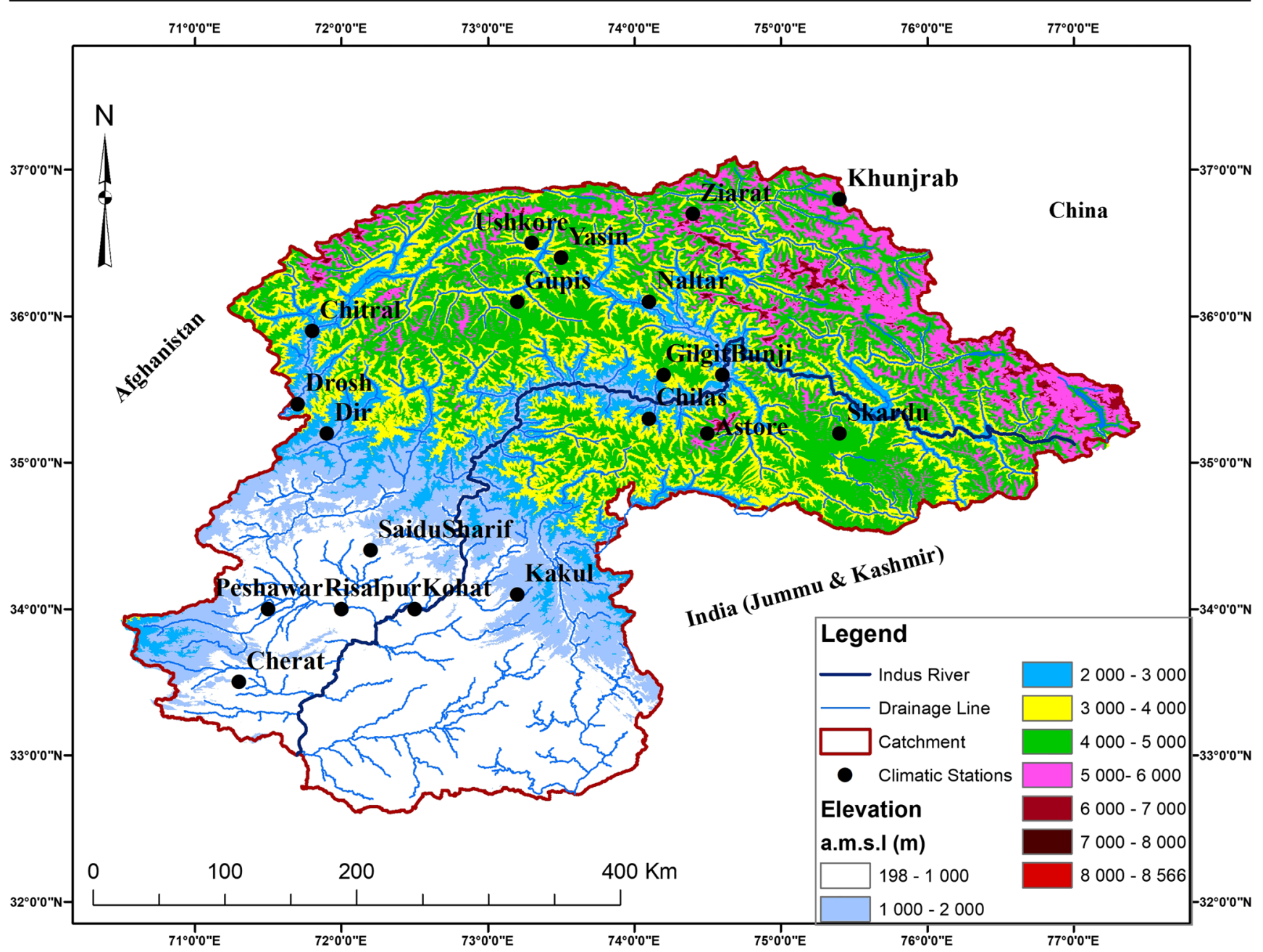

Fig. 1 Climatic stations and sub-basins located in Upper Indus Basin (UIB)

high-altitude stations in this study represent the Karakoram region in Pakistan, thereby representing UIB rather than covering the same basin by the rest of the countries. The UIB in Pakistan encompasses the major sub-basins of Shigar, Shyok, Hunza, Gilgit, Astore covering the Karakoram, Hindukush, and Himalayan regions within Pakistan. The Shyok River carries major runoff generated from the massifs of Baltoro, Biafo, and Batura glaciers in Baltistan Province and joins the Indus River at Skardu (elevation $2700 \mathrm{~m}$ ). Similarly, the Gilgit River contributes its runoff to the Indus River at an altitude of $1524 \mathrm{~m}$, the runoff of which is generated from massifs of Nanga Parbat at a point where the gigantic mountain ranges HKH meet. The UIB holds $11 \%\left(18,500 \mathrm{~km}^{2}\right)$ of the total area of this basin, which is under permanent ice and glacial coverage (RGI4.0- Pfeffer et al. 2014). Pakistan holds almost $46 \%$ of the UIB; approximately $60 \%$ of this region is classified as a cryospheric extent of Pakistan. We have also incorporated the entire Gilgit and Astore Subbasins of UIB, which cover the east portion of Hindukush southeast to the Indus River. We have selected five high-altitude stations that have been set up in this region by Water and Power
Development Authority (WAPDA). The purpose of including these stations is to investigate the high-altitude region climate, which sometimes exhibits a different pattern compared to valley regions. These stations also encompass a region of the Karakoram that is famous for its different hydrological and meteorological behavior such as the Karakoram anomaly (Hewitt 2005). One of the most important steps involves the selection of stations to identify trends in temperature.

\subsection{Data quality assurance}

The data collection procedure in Pakistan is carried out mainly by three organizations, having a limited network of meteorological stations installed within Pakistan's political boundary. These organizations are members of the World Meteorological Organization (WMO) and national-level government agencies and strictly follow all the Standard Operating Procedures (SOPs) regarding setting up of gadgets, acquisition, and propagation of data to handlers (Latif et al. 2016). The Pakistan Meteorological Department (PMD) has installed all instruments according to the criteria established 
by the Indian Meteorological Department (IMD) in 1891, according to Archer and Fowler (2004). The (PMD) mostly collects climatological data, and the (WAPDA) is solely responsible for assimilating hydrological data, while the Snow and Ice Hydrology Project (SIHP) is a major project of WAPDA, which maintains data collection from high-altitude regions. This network entails 12 Data Collection Platforms (DCPs), which transmit hourly data via a Meteor-Burst communication system to the central branch (Hasson et al. 2015). These DCPs are also referred to as Automatic Weather Stations (AWS), which have been installed over the highaltitude region with careful attention to WMO standards. An AWS is generally classified into two additional types by data recording, i.e., real time and archived. This might be either the inclusion of a station that provides data in real time or a station that records data to archive. The selected high-altitude stations are equipped with real-time types of AWS, which promise the transmission of synoptic data and the monitoring of serious situations for declaring an emergency. The core purpose of installing AWS in this region was to establish the homogeneity of networks by standardizing the observation methods. The number of incorrect observations and missing values are minimized automatically by state-of-the-art techniques known as quality control (WMO 1997). The purpose of achieving quality-controlled data samples is ensured by working out each observation from an equitably huge number of qualitycontrolled data, then the sample that caused the error can be isolated from the error-free observations in order to proceed with an uncontaminated analysis.

A carefully designed set of techniques dedicated to sound maintenance practices, repairs, calibrations, and data quality checks may lead to obtaining high quality, consistent data output (WMO 2004). There was no approved set of measures or criteria for the various AWS platforms, but it is recommended that such a set of procedures should be developed and documented (WMO 2003b). Recently, these procedures have been introduced to avoid any uncertainty in data collection and transmission. According to the report (WMO 2004) an AWS usually consists of a resistance thermometer as a temperature sensor, which essentially needs linearization before calibration, as it is recommended that the thermistor characteristics should be linearized. The linearization might be enabled either by suitable circuits in signal conditioning modules or by software algorithms. The radiation effect may contaminate the original reading; to avoid this inconsistency, the sensor should be properly protected from potential radiation impacts. The AWS is equipped with a radiation shield adjusted to the size of the sensor by a naturally ventilated Stevenson screen. Wet bulb effects also cause deterioration at the data acquisition stage, so for an accurate measurement, the radiation shields should be designed by providing manual ventilation having an airspeed of approximately $3 \mathrm{~m} / \mathrm{s}$. The necessary precautions are to secure the sensor from entries of drizzle and aerosols (WMO 2003b).

We have selected twenty climatic stations extending from higher to lower elevations for this study. Locations and physiognomies of the stations are given in Fig. 1 and Table 1, respectively. The available data from high altitude stations are unable to provide long-term records, as they are usually based on a short data period (1995-2013). The selected locations encompass the most critical areas concerning the climatological and hydrological regime of the UIB. These stations installed within the UIB extend approximately $100 \mathrm{~km}$ in a north-south direction from Gupis to Astore, while an extension of approximately $200 \mathrm{~km}$ from Skardu to Gupis has been set up in the east-west direction (Hasson et al. 2015). We have arranged the monthly mean maximum $T_{\max }$, minimum $T_{\min }$, and mean $T_{\text {mean }}$ temperatures from the daily values of these variables.

\section{Material and methods}

Meteorological variables, such as temperature, precipitation and river flows are important indicators of climate change. These variables tend to reflect warming/cooling trends, thereby enabling us to understand the relationship between hydrology and climate. We selected four climatic variables in terms of temperature by which to obtain trend analysis: $T_{\max }, T_{\min }$, $T_{\text {mean }}$, and DTR. We have analyzed trend variability of these variables for four different periods: 1961-2013, 1971-2013, 1981-2013, and 1991-2013.

\subsection{Trend identification}

Trend evaluation involves the determination of a value of a random variable primarily in terms of increasing/decreasing order within a period in statistical terms (Haan 1977). Statistically, any trend might be significant or insignificant based on parametric or non-parametric statistical tests. In the fields of climatology and hydrology, a primary concern is to deal with the trends; for this purpose, non-parametric methods are widely employed. Tests such as the Mann-Kendall (MK) (Mann 1945; Kendall 1975) test, Spearman rank correlation (Dahmen and Hall 1990) test, and Sen's robust slope estimator (SS) (Sen 1968) are used for trends detection and magnitude. Yue and Wang (2004) reported a minor difference between the outcomes based on MK and Spearman rank correlation analysis. Therefore, the MK test and SS method can be employed, respectively, for trend detection and estimation of the magnitude of the trend within any time series (Khaliq et al. 2009). We carried out analyses for the time series of mean, minimum, and maximum temperature; these steps involved: (1) applying 
Table 1 List of climatic stations used in the present study and their characteristics

\begin{tabular}{|c|c|c|c|c|c|c|c|c|}
\hline \multirow[t]{2}{*}{ Sr. no. } & \multirow[t]{2}{*}{ Station } & \multirow{2}{*}{$\begin{array}{l}\text { Lat. } \\
\text { (dd) }\end{array}$} & \multirow{2}{*}{$\begin{array}{l}\text { Lon. } \\
\text { (dd) }\end{array}$} & \multirow{2}{*}{$\begin{array}{l}\text { Elevation } \\
\text { (m) }\end{array}$} & \multicolumn{3}{|c|}{ Mean annual temperature $\left({ }^{\circ} \mathrm{C}\right)$} & \multirow[b]{2}{*}{ DTR } \\
\hline & & & & & Max. & Min & Mean & \\
\hline 1 & Astore & 35.2 & 74.5 & 2168.0 & 15.6 & 4.1 & 9.84 & 11.5 \\
\hline 2 & Bunji & 35.6 & 74.6 & 1372.0 & 23.8 & 11.4 & 17.6 & 12.4 \\
\hline 3 & Cherat & 33.5 & 71.3 & 1372.0 & 21.5 & 13.2 & 17.3 & 8.3 \\
\hline 4 & Chilas & 35.3 & 74.1 & 1250.0 & 26.4 & 14.1 & 20.1 & 12.3 \\
\hline 5 & Chitral & 35.9 & 71.8 & 1497.8 & 23.3 & 8.6 & 15.9 & 14.7 \\
\hline 6 & Dir & 35.2 & 71.9 & 1375.0 & 22.9 & 8 & 15.4 & 14.8 \\
\hline 7 & Drosh & 35.4 & 71.7 & 1463.9 & 24.1 & 11.3 & 17.6 & 12.8 \\
\hline 8 & Gilgit & 35.6 & 74.2 & 1460.0 & 23.9 & 7.6 & 15.8 & 16.3 \\
\hline 9 & Gupis & 36.1 & 73.2 & 2156.0 & 18.7 & 6.7 & 12.6 & 12 \\
\hline 10 & Kakul & 34.1 & 73.2 & 1308.0 & 22.8 & 10.9 & 16.9 & 11.9 \\
\hline 11 & Kohat & 34.0 & 72.5 & 1440.0 & 29.3 & 16.9 & 23.3 & 12.4 \\
\hline 12 & Khunjrab & 36.8 & 75.4 & 4440.0 & -0.7 & -9.6 & -5.0 & 8.9 \\
\hline 13 & Naltar & 36.1 & 74.1 & 2898.0 & 10.9 & 1.1 & 5.9 & 9.8 \\
\hline 14 & Peshawar & 34.0 & 71.5 & 320.0 & 29.5 & 16.1 & 22.8 & 13.4 \\
\hline 15 & Risalpur & 34.0 & 72.0 & 575.0 & 29.6 & 14.5 & 21.9 & 15.1 \\
\hline 16 & SaiduSharif & 34.4 & 72.2 & 961.0 & 26 & 12 & 19.2 & 14 \\
\hline 17 & Skardu & 35.2 & 75.4 & 2317.0 & 18.6 & 4.9 & 11.7 & 13.7 \\
\hline 18 & Ushkore & 36.5 & 73.3 & 3051.0 & 9.8 & 1.16 & 5.49 & 8.64 \\
\hline 19 & Yasin & 36.4 & 73.5 & 3280.0 & 8.6 & 0.49 & 4.6 & 8.11 \\
\hline 20 & Ziarat & 36.7 & 74.4 & 3629.0 & 7.7 & -2.2 & 2.8 & 9.9 \\
\hline
\end{tabular}

the Mann-Kendall test for testing the serial correlation effect and (2) trend detection.

\subsection{Effect of serial correlation}

Kulkarni and Von Storch (1999) reported that most time series investigations involve autocorrelation. During analysis of time series data, the presence of a positive serial correlation (persistence) allows a non-parametric test to present the significance level of a trend. Before applying the MK test, Von Storch and Navarra (1999) suggested pre-whitening to remove the effect of the serial correlation test. Yue and Wang (2004) further improved the pre-whitening technique to trend-free pre-whitening (TFPW) for the time series having autocorrelation. This improved technique for trend identification had been widely applied previously for studies regarding hydrology, climatology and meteorology such as (Yue et al. 2002; Aziz and Burn 2006; Novotny and Stefan 2007; Kumar et al. 2009; Oguntunde et al. 2011). The present study employs this method to detect trends in temperature observations $\left(x_{1}, x_{2}, . \cdot X_{n}\right)$, which are examined using the following procedures:

1. A slope of the increasing/decreasing trend $(\beta)$ is calculated using Sen's slope estimator. If a time series already has a trend, it is removed before assuming a linear trend as follows:

$$
Y_{i}=x_{i}-(\beta \times i)
$$

where $(\beta)$ is the slope and $x_{1}$ denotes the successive data; $n$ presents the length of data.

2. Autocorrelation $\left(r_{1}\right)$ is calculated.

3. Statistical tests are applied to the time series data if the calculated $r_{1}$ does not present a significant value at the $5 \%$ level. In case of a significant value of $r_{1}$ before applying tests, the "pre-whitened" time series is calculated using the following relation given as follows:

$$
\bar{Y}_{i}=Y_{i}-r Y_{1-i}+(\beta \times i)
$$

where $Y_{i}$ denotes the original time series.

\subsection{Statistical tests}

The MK test is the most commonly used statistical tool for investigating trends in climatological time series (Rio et al. 2005, Bhutiyani 2007, Mavromatis and Stathis 2011, Caloiero et al. 2011, Tabari et al. 2012). Some authors also used this test for trends in hydrological time series (e.g., Yue and Wang 2004). The MK test is useful in trend identification 
analyses for two main reasons. In the case of this test, time series data should not necessarily be normally distributed. Second, it is insensitive to the data outliers and missing values and less sensitive to the breaks caused by inhomogeneous time series (Bocchiola and Diolaiuti 2013, Tabari et al. 2011; Jaagu's 2006).

The Mann-Kendall statistic $Z_{\mathrm{mk}}$, was evaluated as follows:

$Z_{\mathrm{mk}}=\left\{\begin{array}{c}\frac{S-1}{\sigma_{s}} \text { if } S>0 \\ 0 \text { if } \quad S=0 \\ \frac{S+1}{\sigma_{s}} \text { if } \quad S<0\end{array}\right\}$

where $S$ denotes the test statistic, which is calculated by the following equation:

$S=\sum_{k=1}^{n-1} \sum_{j=k+1}^{n} \operatorname{sgn}\left(x_{j}-x_{k}\right)$

where $n$ denotes total years within a time series, and $x_{j}$ and $x_{k}$ are the annual values of years $j$ and $k$ respectively. The function $\operatorname{sgn}\left(x_{j}-x_{k}\right)$ is an indicator function that takes the value 1 , 0 , or -1 depending on the sign of difference $\left(x_{j}-x_{k}\right)$, where $j>k$ as follows:

$\operatorname{sgn}(x j-x k)=\left\{\begin{array}{cc}1 & \text { if } x_{j}-x_{k}>0 \\ 0 & \text { if } x_{j}-x_{k}=0 \\ -1 & \text { if } x_{j}-x_{k}<0\end{array}\right\}$

$\mathrm{Z}_{\mathrm{mk}}$ designates an upward and downward trend exhibiting warming and cooling, respectively, for a positive and negative value for a station. The trend becomes significant if the probability under the null hypothesis $H_{\mathrm{o}}$, following a standard normal distribution of $(S)$ is greater than the test statistic $Z_{\mathrm{mk}}$ for the selected significance level $\alpha$. In case of the absence of a trend, the null hypothesis $H_{\mathrm{o}}$ becomes true following a standard normal value to choose whether reject $H_{\mathrm{o}}$ will be rejected. The two-tailed test is also applied for the detection of whether either a warming or cooling pattern exists at the $\alpha$ level of significance. Similarly, $H_{\mathrm{o}}$ is rejected if the absolute value of $Z_{\mathrm{mk}}>Z_{1-a / 2}$ at the same level of significance.

\subsection{Sen's slope estimator}

The changing trends of temperature for each period are assessed by Sen's method (Sen 1968). The slope enables the estimation of $N$ pairs of data using the relation as follows:

$Q_{i}=\frac{x_{j-} x_{k}}{j-k} \quad$ if $j>k$

where the annual values of years $j$ and $k$ were denoted by $x_{j}$ and $x_{k}$, respectively. $N$ values of $Q$ represented Sen's slope estimator of the median. We obtained this median of the $N$ using standard methods. The smallest to largest $N$ values of $Q_{i}$ were ranked and the Sen's estimator used the following equation:

Sen's estimator

$$
=\left\{\begin{array}{cl}
Q_{\left[\frac{(N+1)}{2}\right]} & \text { if } N \text { was odd } \\
\frac{1}{2}\left(Q_{\frac{N}{2}}+Q_{[(N+2) / 2)]}\right) & \text { if } N \text { was even }
\end{array}\right\}
$$

Non-parametric tests are commonly used to measure the confidence interval and the correct slope of a trend.

\subsection{Assessment of inhomogeneity}

The relative climatic homogeneity was introduced by (Conrad and Pollak 1950) to remove the non-climatic influences in the time series. These non-climatic factors, such as recording gauge relocation and different procedural and observational changes, might be able to create the discontinuity in time series data resulting in inaccuracy (Costa and Soreas 2008). Aguilar et al. (2003) reported that a homogeneous climate time series is defined as one where variations are caused only by climatic change. They also proposed that "it is important, therefore, to remove the inhomogeneity or at least to determine the possible error they may cause." WMO (1983) defined a climatic normal as a period of a climatic element temperature/precipitation calculated for a more extended and normal period of three consecutive 10 -year periods. These normals are usually calculated for 30 years beginning at the start of a decade. If the available data reflect both current observation practices and climate at the particular station, then averages for a shorter period (10 years) can also be acceptable in case of unavailability of a 30-year data record (Guttman 1998). The same author also proposed that the non-climatic factors in actual practice, such as moving of observing sites and instrument, installation of a new instrument, changing observing methods and codes, and sensor calibration/ changing are not constant.

\subsection{Standard normal homogeneity test (SNHT)}

Alexandersson (1986) reported a statistic $T(k)$ to compare the mean of the first $k$ years of the record with that of the last $n-$ $k$ years as follows:

$$
\begin{aligned}
& T(k)=k \bar{z}_{1}^{2}+(n-k) \bar{z}_{2}^{2} \quad k=1, \ldots, n \\
& \bar{z}_{1}=\frac{1}{k} \sum_{i=1}^{k}\left(Y_{i}-\bar{Y}\right) / s \text { and } \bar{z}_{2}=\frac{1}{n-k} \sum_{i=k+1}^{n}\left(Y_{i}-\bar{Y}\right) / s
\end{aligned}
$$

where 
When a break is observed at the year $K$, then $T(k)$ reaches a maximum near the year $k=K$. The test statistic $T_{0}$ is calculated as follows:

$$
T_{0}={ }_{1 \leq k<n}^{\max } T(k)
$$

A similar test was further studied by Jaruskova (1994). The following equation gives the relationship between test statistic $T(n)$ and $T_{\mathrm{o}}$ :

$$
T_{0}=\frac{n(T(n))^{2}}{n-2+(T(n))^{2}}
$$

\subsection{Homogenization of temperature time series}

We have applied a common method of Multiple Analysis of Series for Homogenization (MASH) used by Szentimrey 2008. This method follows a relative approach for the detection and correction of inhomogeneity in the temperature time series. The purpose of applying this method was to make the assurance of an extensive trend identification as precise as possible so that it could be used to explain the climate of this region more reliably. The trend analysis becomes doubtful and unable to present likely outcomes of the climate and its provoking effects if it contains artificial shifts and biased data. The sole purpose of adopting this particular method involved unavailability of metadata from all the stations used in the present study. The MASH can use metadata automatically instead, giving as input values: This method is breifly explained as follows; where $Z j$ and $X j$ are optimal difference in time series and candidate time series; $\mathrm{IH}_{j}(\mathrm{t})$ denotes inhomogeneity; $\Sigma i \neq j \lambda i X i(t)$ is the sum of reference series; $\lambda i$ is wighing facor which eliminates the noise $\varepsilon_{z j}(\mathrm{t})$. The resulting vector is given in eq. 13 where $C_{c, \text { ref }}$ represents covarience vector of reference and candidate time series and $C_{c, \text { ref }}$ shows covarience matrix of reference time series.

$$
\begin{aligned}
& Z_{j}(t)=X_{j}(t)-\sum_{i \neq j} \lambda_{i} X_{i}(t)=\mathrm{IH}_{j}(t)-\sum_{i \neq j} \lambda_{i} \mathrm{IH}_{i}(t) \\
& +\varepsilon_{z_{j}}(t) \mu \varepsilon(j=1,2, \ldots N) \\
& \lambda_{i}=C_{r e f}^{-1}\left(C_{c, r e f}+\frac{\left(1-1^{T} C_{r e f}^{-1} c, r e f\right.}{1^{T} C_{r e f}^{-1} 1} 1\right)
\end{aligned}
$$

\section{Results and discussion}

\subsection{High-altitude temperature range}

We presented annual and seasonal temperature for eight meteorological stations (> 2000 m.a.s.l) in the form of a box-and- whisker plot to provide a detailed distribution of data. The principal objective for including high-altitude stations is to investigate the effect of high-altitude warming. Widespread trend analysis of these stations is also carried out to evaluate warming/cooling trends versus elevation. The median annual $T_{\max }$ of Khunjrab (4440 m.a.s.1) station remains at $-1^{\circ} \mathrm{C}$, and the maximum value ranges below $0{ }^{\circ} \mathrm{C}$, as shown in Fig. 2 . Similarly, the minimum temperature remains below $-2{ }^{\circ} \mathrm{C}$. For the autumn, the median is in the $0{ }^{\circ} \mathrm{C}$ range, and the maximum and minimum range between 1 and $-1{ }^{\circ} \mathrm{C}$. The spring median remains above $0{ }^{\circ} \mathrm{C}$, and temperature mostly falls above this temperature range. We also noted outliers in data ranging from -1 to $-2{ }^{\circ} \mathrm{C}$. The summer median remains at $9{ }^{\circ} \mathrm{C}$, and minimum temperature ranges between 8 and $10{ }^{\circ} \mathrm{C}$. We noted an outlier at $5{ }^{\circ} \mathrm{C}$ during 2007 for the Khunjrab station. During the winter, the median remains at $-11{ }^{\circ} \mathrm{C}$, and most values remain below $-10{ }^{\circ} \mathrm{C}$. We noted outliers in data during (2005-2008) at $-7{ }^{\circ} \mathrm{C}$ and $-12{ }^{\circ} \mathrm{C}$, respectively. We present a comprehensive statistical data distribution in Figs. 3 and 4 for the minimum and mean temperature, respectively, of these high-altitude stations.

\subsection{Inhomogeneity in temperature time series}

We have applied the SNHT test to assess the inconsistency in temperature time series for the low-altitude stations rather than including high-altitude (DCP) stations due to homogenous and high-quality data assurance (Hasson et al. 2015). Our analysis exhibited inhomogeneity at eight stations in maximum and minimum temperature as shown in Table 2. Previous studies reported the inhomogeneity in minimum temperature at Bunji (Archer and Fowler 2004) and annual mean temperature at Gilgit, Skardu, and Astore (Forsythe et al. 2014) and at Gilgit, Gupis, Astore, and Skardu (Rio et al. 2011). Whereas the recent studies (Khattak et al., 2011; Bocchiola and Diolaitia 2013; Minora et al. 2013) were unable to address the homogeneity of time series data, Hasson et al. (2015) reported the inhomogeneity in minimum temperature at low-altitude stations including Astore, Bunji, Chilas, Gilgit, and Gupis with the exception of Skardu. Our results are inconsistent with the above mentioned studies, as we found inhomogeneity in the record of the maximum temperature at Bunji, Chitral, Gupis, Skardu, and Risalpur, whereas the minimum temperature inhomogeneity was observed at Drosh, Gilgit, Kohat, and Skardu. Due to already scarce data availability and a limited number of stations, we were unable to exclude such stations from the time series analysis whose homogeneity was compromised for a singular year. This issue was resolved due to creating further four-time series as inhomogeneity was observed in different time series rather than the entire data length. We have mentioned the stations in each time series in figures, where data were not homogenous for 


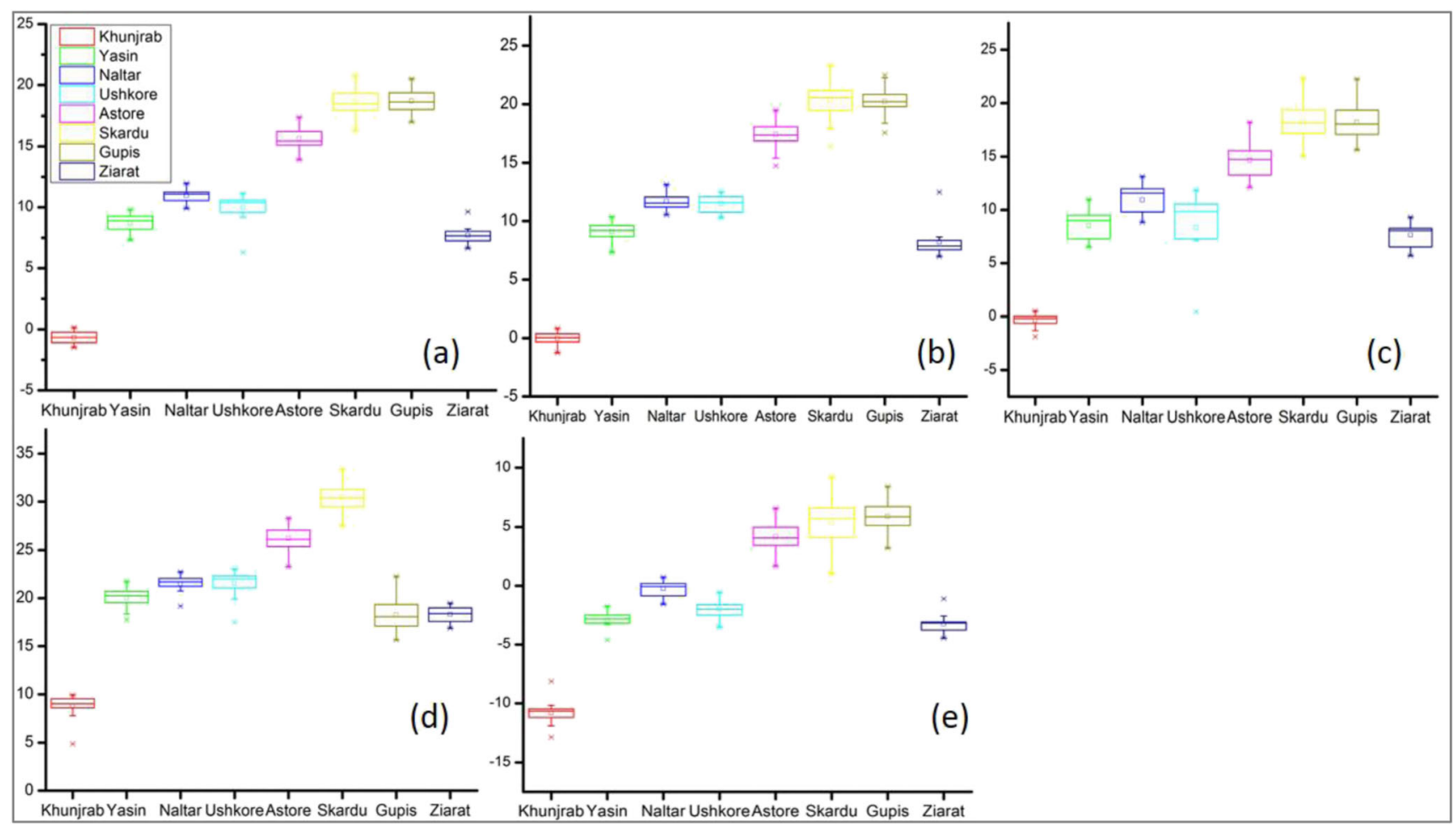

Fig. 2 Box and whisker representation of high altitude stations data $\left(T_{\max }\right)$

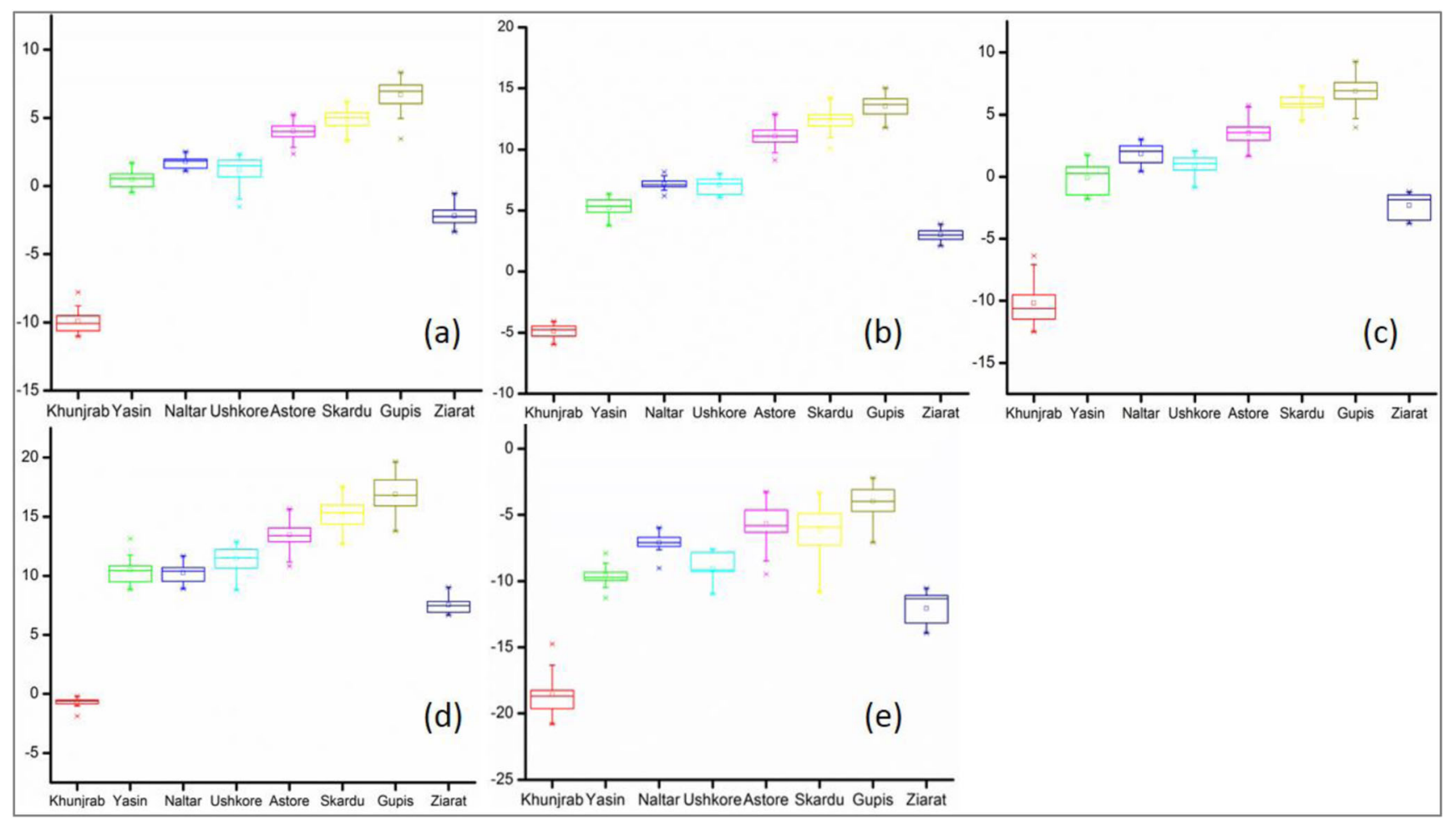

Fig. 3 Box and whisker representation of high altitude stations data $\left(T_{\min }\right)$ 


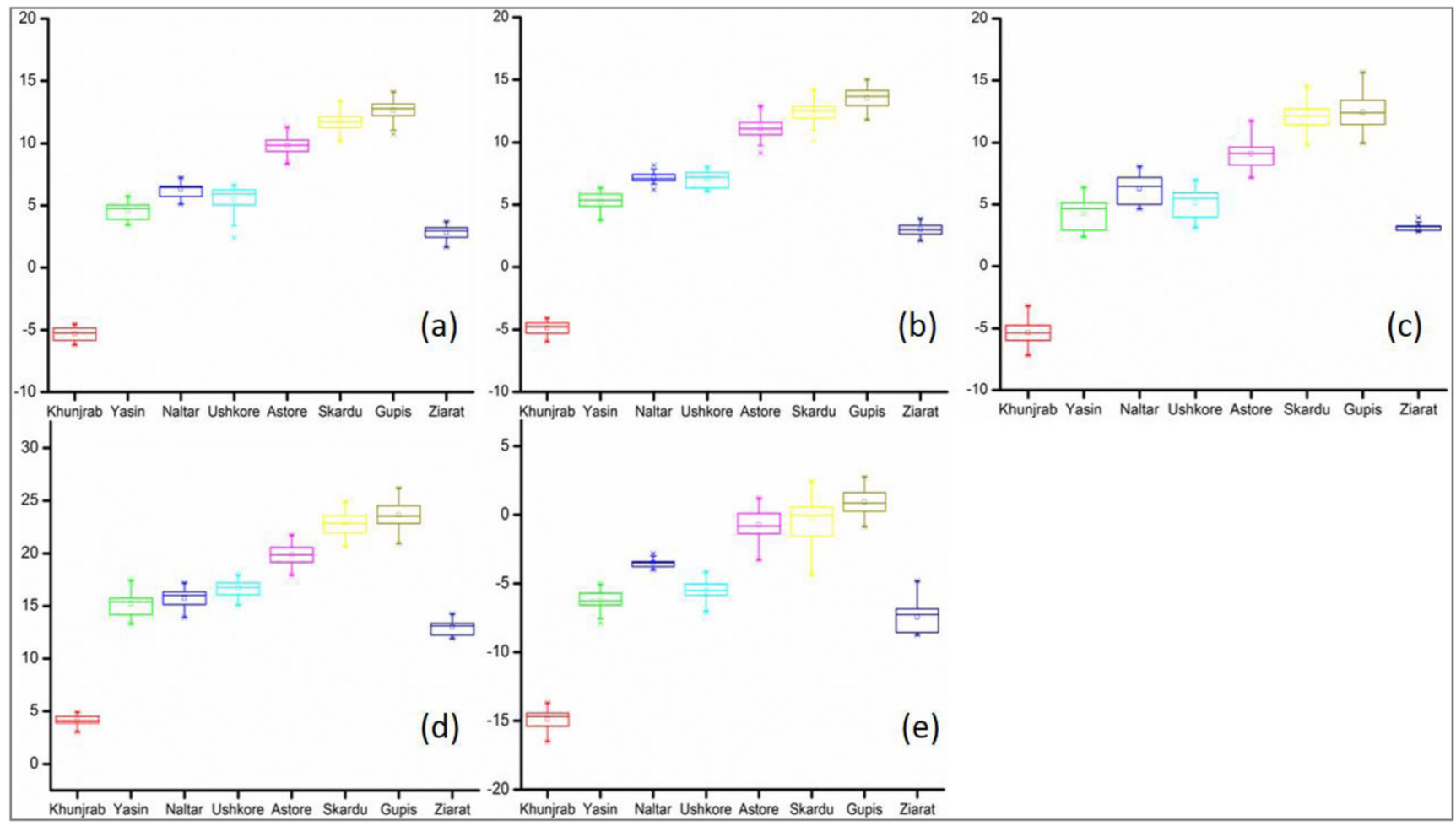

Fig. 4 Box and whisker representation of high altitude stations data $\left(T_{\text {mean }}\right)$

the specific stations, in order to avoid any doubt in regarding the trend analysis (Table 2 and 3).

\subsection{Trends in maximum temperature}

Climatic conditions of the UIB are extremely variable regarding temperature. During the first data series, we found significant negative trends at Chilas and Cherat, at rates of 0.15 and $0.23{ }^{\circ} \mathrm{C} /$ decade, and positive trends at Skardu and Risalpur, at rates of 0.34 and $0.92{ }^{\circ} \mathrm{C} /$ decade. During the second time series, Bunji, Chilas, Peshawar, and Risalpur showed significant negative trends, at rates of $0.51,0.26,0.32$, and $0.16^{\circ} \mathrm{C} /$ decade. During the third data series, Bunji, Peshawar, and Risalpur showed downward trends at rates of $0.67,0.24$, and

Table 2 Inhomogeneous stations and change point during (1961-2013) tested by XLSTAT and SNHT

\begin{tabular}{llll}
\hline Stations & Monte Carlo trials & SNHT $\left(T_{\max }\right)$ & SNHT $\left(T_{\min }\right)$ \\
\hline Bunji & Bunji & $1972(16.242)$ & \\
Chitral & Gilgit & $1986(9.690)$ & $1985(11.681)$ \\
Drosh & & & $1968(5.938)$ \\
Gupis & & $1968(15.465)$ & $1986(16.06)$ \\
Gilgit & & $1986(16.656)$ & $1989(13.54)$ \\
Skardu & & $1997(10.78)$ & \\
Risalpur & & & $1997(15.103)$ \\
Kohat & & &
\end{tabular}

$0.11{ }^{\circ} \mathrm{C} /$ decade; only Skardu showed an upward trend, at a rate of $0.34{ }^{\circ} \mathrm{C} /$ decade (Fig. $5 \mathrm{c}$ upper). During the fourth data series, Bunji, Gupis, Kohat, Risalpur, Naltar, Skardu, Yasin, and Ziarat showed significant negative trends, at rates of 0.22 , $0.6,0.11,0.21,0.7,0.39,0.9$, and $0.4^{\circ} \mathrm{C} /$ decade, respectively, while Drosh, Peshawar, and Khunjrab showed positive trends, at rates of $0.18,0.39$, and $0.61{ }^{\circ} \mathrm{C} /$ decade (Fig. 7a). Seasonally, we found a pattern of downward trends during the summer at Astore, Bunji, Chitral, Drosh, Gilgit, Gupis, Kakul, Kohat, Naltar, Peshawar, Risalpur, Yasin, and Ziarat, at rates of $0.31,0.86,0.46,0.22,0.14,0.2,0.4,0.36,0.29$, $0.21,0.34,0.81$, and $0.5^{\circ} \mathrm{C} /$ decade, respectively, during the fourth series. During the winter, we noted significant downward trends at Astore, Chitral, Dir, Drosh, Gupis, Khunjrab, Naltar, Peshawar, Risalpur, Saidu Sharif, Ushkore, Yasin, and Ziarat at rates of $1.13,0.9,0.25,0.34,0.19,0.81,0.8,0.12$, $0.21,0.86,0.5,0.4$, and $0.3{ }^{\circ} \mathrm{C} /$ decade during the fourth data series. On the other hand, we noted significant upward trends during the autumn at Bunji, Chitral, Cherat, Drosh, Gupis, Kakul, Khunjrab, Saidu Sharif, and Ziarat, at rates of 0.1, $0.48,0.13,0.27,0.29,0.13,0.36,0.61$, and $0.43{ }^{\circ} \mathrm{C} /$ decade during the fourth series (Fig. 7b). Our findings are inconsistent with seven stations within UIB showing increased annual maximum temperature analyzed by Fowler and Archer (2006). However, our results supported the results of (Hasson et al. 2015), who noted dominant cooling trends in the UIB at the stations examined in this study (Chilas, Gilgit, and Skardu). 
Table 3 Inhomogeneous stations and change point during (1961-2013) tested by MASH

\begin{tabular}{|c|c|c|c|c|c|c|c|c|c|c|c|}
\hline \multicolumn{2}{|l|}{ Astore } & \multicolumn{2}{|l|}{ Bunji } & \multicolumn{2}{|l|}{ Cherat } & \multicolumn{2}{|l|}{ Chilas } & \multicolumn{2}{|l|}{ Dir } & \multicolumn{2}{|l|}{ Giligit } \\
\hline $1961^{* *}$ & 4.92 & $1981^{*}$ & 0.97 & $1966^{*}$ & 0.12 & 1979 & -0.23 & $1994^{*}$ & -0.01 & $1962^{* *}$ & -0.16 \\
\hline $1993^{*}$ & -0.34 & $1999^{*}$ & -0.60 & $2003^{*}$ & -1.04 & $2005^{*}$ & -0.21 & $2003^{*}$ & -0.10 & $2005^{*}$ & 0.05 \\
\hline $2000^{*}$ & 0.11 & $2011^{* * *}$ & 1.09 & & & & & $2010^{*}$ & -0.05 & $2012^{* *}$ & -1.63 \\
\hline $2012^{*}$ & -0.09 & & & & & & & & & & \\
\hline \multicolumn{2}{|l|}{ Kakul } & \multicolumn{2}{|c|}{ Saidu Sharif } & \multicolumn{2}{|c|}{ Skardu } & & & & & & \\
\hline $1967^{* *}$ & 0.03 & $1967^{*}$ & 0.03 & $1977^{*}$ & -0.06 & & & & & & \\
\hline \multirow[t]{3}{*}{$1991^{*}$} & -0.06 & $2005^{* *}$ & -0.24 & $1984^{*}$ & -0.04 & & & & & & \\
\hline & & & & $2001^{*}$ & -0.16 & & & & & & \\
\hline & & & & $2004^{*}$ & 0.07 & & & & & & \\
\hline
\end{tabular}

*Maximum temperature; **Minimum temperature

\subsection{Trends in minimum temperature}

We observed inhomogeneous data of minimum temperature at Chitral, Drosh, Gupis, Gilgit, and Kohat, as shown in Table 2. We found a pattern of significant negative trends for $T_{\min }$ similar to those noted for $T_{\max }$. We found significant negative trends at Bunji, Chilas, Cherat, Dir, Drosh, Gupis, Kakul, Risalpur, and Skardu, at rates of 0.34, 0.25, 0.17, 0.14, 0.39, 0.45 , and $0.89^{\circ} \mathrm{C} /$ decade, respectively (Fig. 5a, lower), while Astore, Chitral, and Kohat exhibited significant positive trends, at rates of $0.38,0.24$, and $0.65^{\circ} \mathrm{C} /$ decade, respectively. During the second series, almost equal numbers of stations showed upward, and downward, trends; 14 out of 15 were found significant. Chilas, Karakul, Kohat, Risalpur, Saidu Sharif, and Skardu showed significant positive trends, at rates of $0.18,0.22,0.31,0.55,0.19,0.15$, and $0.34{ }^{\circ} \mathrm{C} /$ decade while negative trends were observed at Bunji, Chitral, Cherat, Dir, Drosh, Gilgit, and Gupis, at rates of $0.34,0.25,0.17,0.14$, $0.39,0.45$, and $0.89^{\circ} \mathrm{C} /$ decade, respectively. During the third series, nine out of fifteen stations exhibited significant trends,

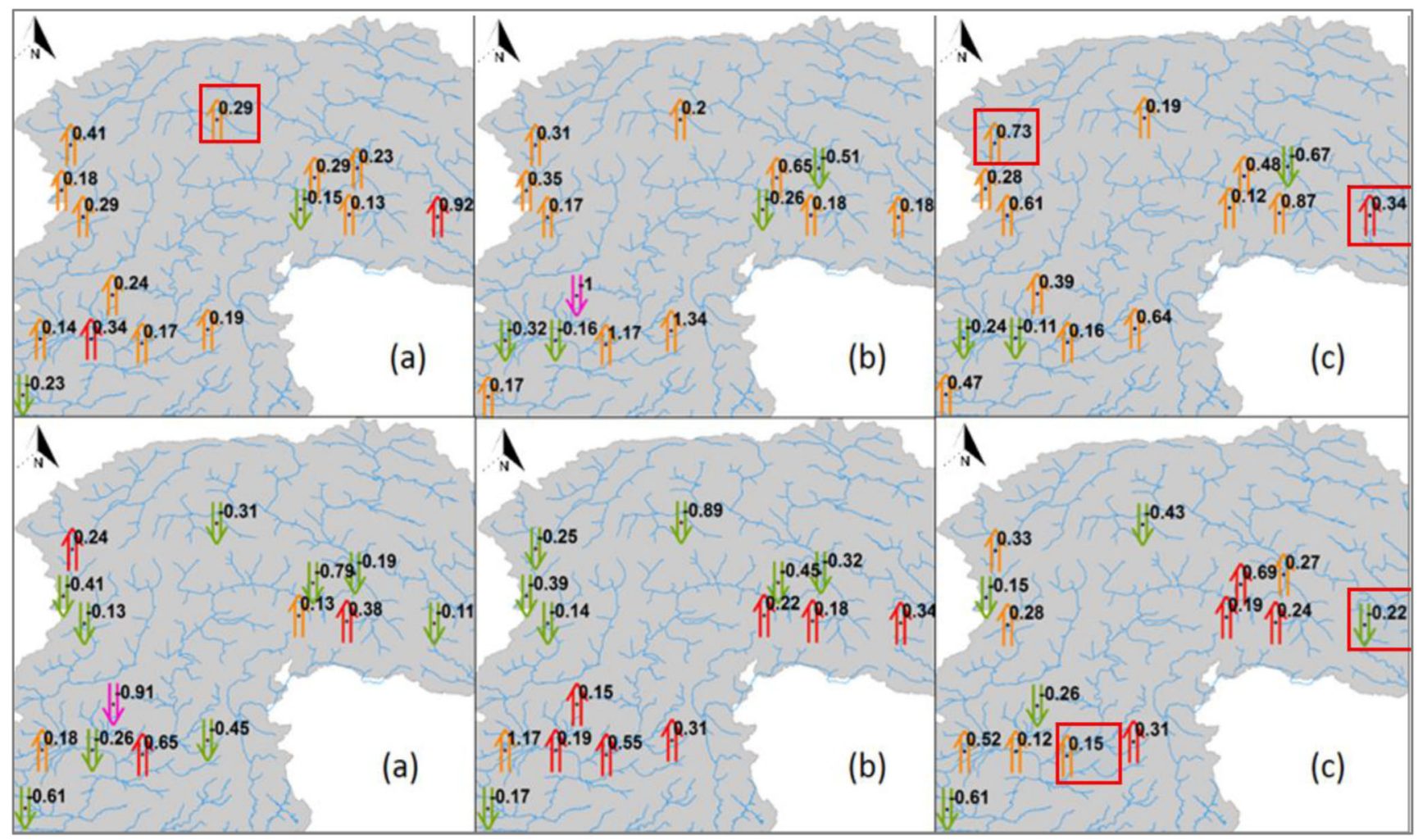

Fig. 5 Spatial distribution of trends in $T_{\max }$ (upper) and $T_{\min }$ (lower) temperature showing change in ${ }^{\circ} \mathrm{C}$ decade ${ }^{-1}$ over time windows in: a 1961-2013, b 1971-2013, c 1981-2013 (upward and downward arrow shows positive and negative trends, yellow and pink (insignificant), red and green (significant trends at $\alpha=0.1$ ). *Red square box showing the station with inhomogeneous data 


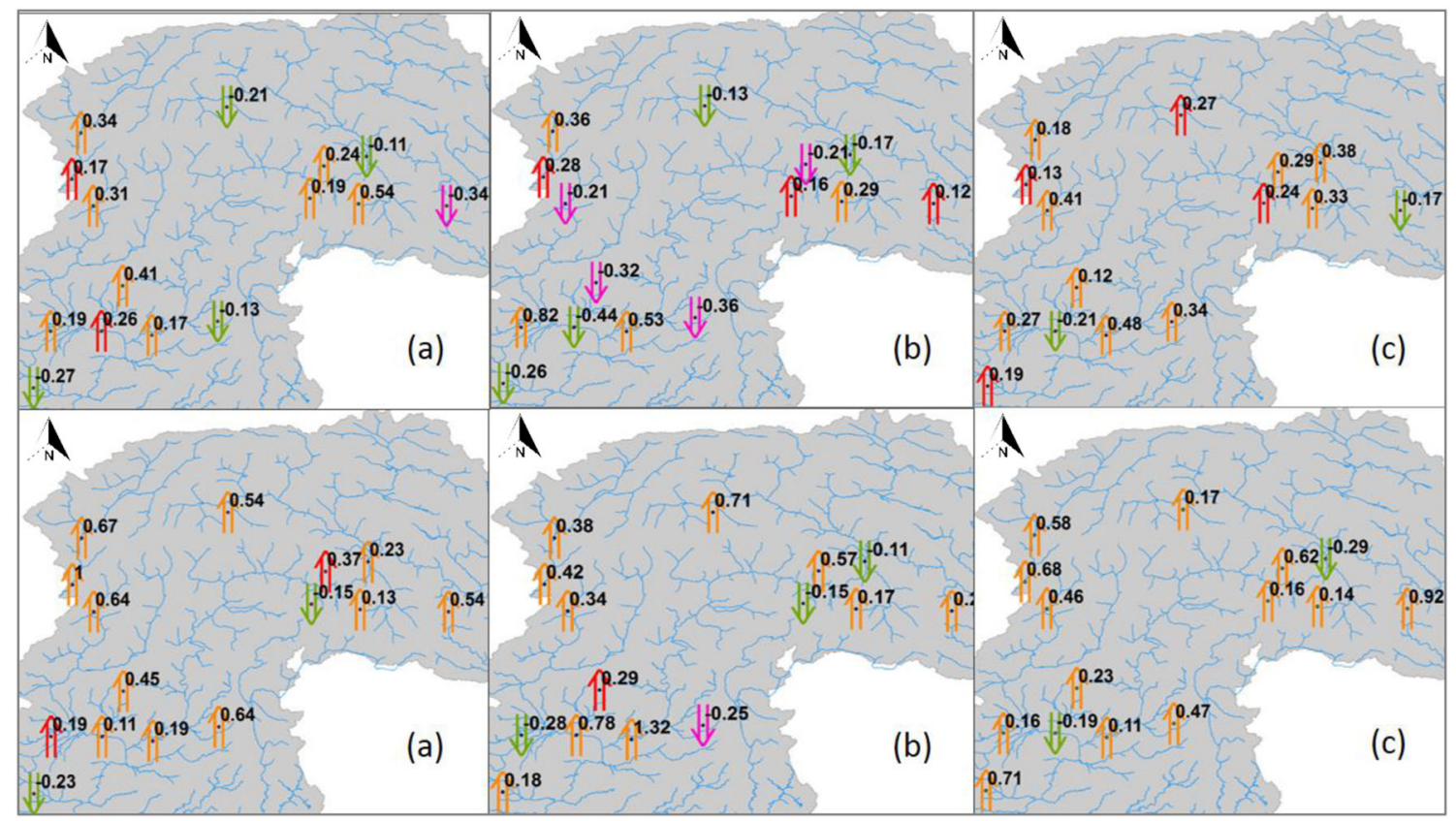

Fig. 6 Spatial distribution of trends in $T_{\text {mean }}$ (upper) and DTR (lower) temperature showing change in ${ }^{\circ} \mathrm{C}$ decade ${ }^{-1}$ over time windows in: a 1961-2013, b 1971-2013, c 1981-2013 (upward and downward arrow

five of which were dominantly negative trends. Cherat, Drosh, Gupis, Saidu Sharif, and Skardu showed downward trends, at rates of $0.61,0.15,0.43,0.26$, and $0.22^{\circ} \mathrm{C} /$ decade, respectively, while Astore, Chilas, Gilgit, and Kakul showed upward trends, at rates of $0.24,0.19,0.69$, and $0.31^{\circ} \mathrm{C} /$ decade, respectively. We found that seven out of twenty stations dominantly exhibited cooling at eight stations (Fig. 8a). Cherat, Drosh, shows positive and negative trends, yellow and pink (insignificant), red and green (significant trends at $\alpha=0.1$ )

Gupis, Kakul, Naltar, Skardu, Ushkore, and Yasin exhibited negative trends, at rates of 0.6, 0.84, 0.4, 0.14, 0.7, 0.37, 0.31, and $0.6{ }^{\circ} \mathrm{C} / \mathrm{dec}$ ade, respectively. Only three stations, Astore, Dir, and Ziarat, showed significant positive trends, at rates of $0.17,0.19$, and $0.63{ }^{\circ} \mathrm{C} /$ decade, respectively.

We noted a similar pattern of downward trends seasonally. During the winter, 12 stations exhibited significant downward

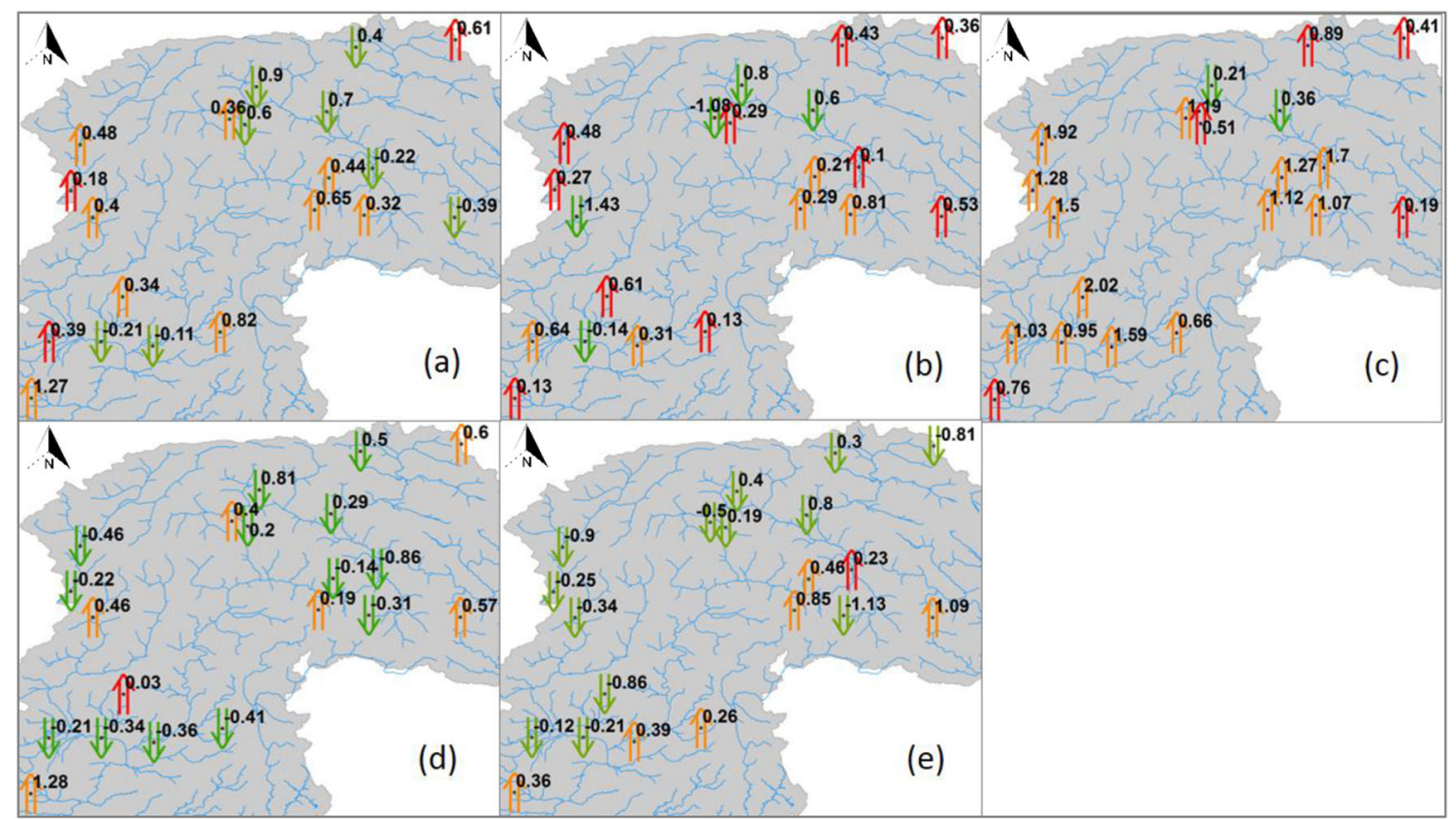

Fig. 7 Spatial distribution of trends for $T_{\max }$ temperature showing change in ${ }^{\circ} \mathrm{C}$ decade ${ }^{-1}$ during (1991-2013). a Annual. b Autumn. c Spring. d Summer. e Winter. (upward and downward arrow shows positive and negative trends, yellow and pink (insignificant), red and green (significant trends at $\alpha=0.1$ ) 


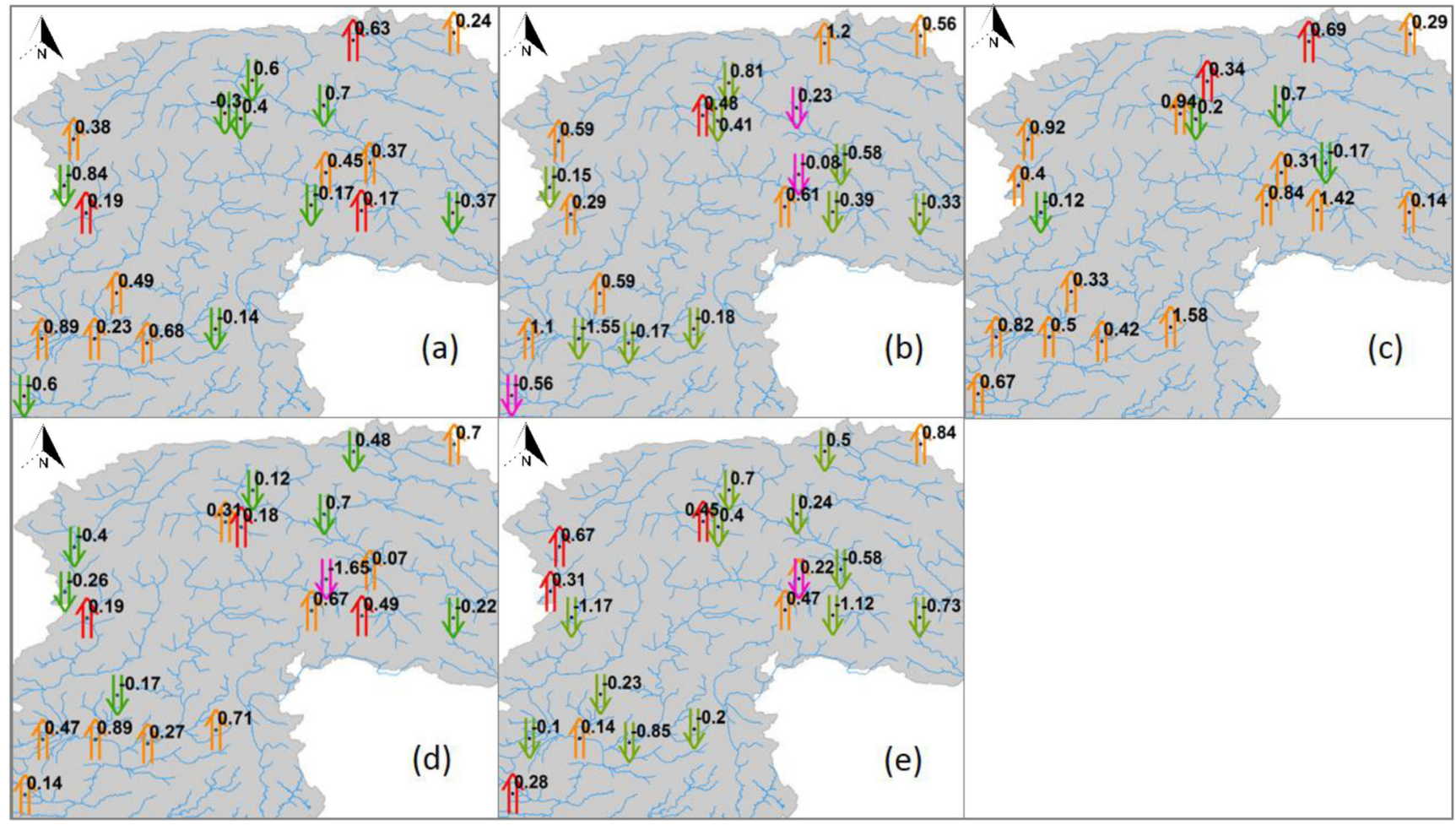

Fig. 8 Spatial distribution of trends for $T_{\min }$ temperature showing change in ${ }^{\circ} \mathrm{C}$ decade ${ }^{-1}$ during (1991-2013). a Annual. b Autumn. c Spring. d Summer. e Winter. (upward and downward arrow shows positive and negative trends, yellow and pink (insignificant), red and green (significant trends at $\alpha=0.1$ )

trends: Astore, Gilgit, Gupis, Dir, Kakul, Kohat, Peshawar, Saidu Sharif, Skardu, Naltar, Yasin, and Ziarat, at rates of $1.12,0.58,0.4,1.17,0.2,0.85,0.1,0.23,0.73,0.24,0.7$, and $0.5{ }^{\circ} \mathrm{C} /$ decade, respectively. Chitral, Cherat, Drosh, and Ushkore showed significant upward trends, at rates of 0.67 , $0.28,0.67$, and $0.45^{\circ} \mathrm{C} /$ decade, respectively. During the autumn, most of the stations exhibited significant downward trends: Astore, Bunji, Drosh, Kakul, Kohat, Risalpur, Skardu, and Yasin, at rates of 0.39, 0.58, 0.15, 0.18, 0.17, $1.55,0.33$, and $0.81{ }^{\circ} \mathrm{C} /$ decade, respectively (Fig. 8b). Only Ushkore showed a significant upward trend, at a rate of $0.48^{\circ} \mathrm{C} /$ decade. We noted a significant downward trend during the summer at Chitral, Drosh, Saidu Sharif, Skardu, Naltar, Yasin, and Ziarat, at rates of 0.4, 0.26, 0.17, 0.22, $0.7,0.12$, and $0.48^{\circ} \mathrm{C} /$ decade. Only Astore, Dir, and Gupis showed significant upward trends, at rates of $0.49,0.19$, and $0.18^{\circ} \mathrm{C} /$ decade. During the spring, Bunji, Dir, Gupis, and Naltar revealed significant cooling, at rates of $0.17,0.2$, 0.12 , and $0.7^{\circ} \mathrm{C} /$ decade. Only Yasin and Ziarat exhibited significant upward trends, at rates of 0.34 and $0.69^{\circ} \mathrm{C} /$ decade.

\subsection{Trends in mean temperature}

We found significant negative trends in $T_{\text {mean }}$ at Bunji, Cherat, Gupis, and Kakul, at rates of $0.21,0.11,0.27$, and $0.31{ }^{\circ} \mathrm{C} /$ decade, respectively (Fig. 6a, upper). However, Drosh and Risalpur showed significant positive trends, at rates of 0.17 and $0.26{ }^{\circ} \mathrm{C} /$ decade. During the second series, Bunji, Cherat, Gupis, and Risalpur exhibited significant negative trends of $0.26,0.17,0.13$, and $0.44{ }^{\circ} \mathrm{C}$ decade, respectively, while Chilas, Drosh, and Skardu showed significant positive trends, of $0.16,0.28$, and $0.12{ }^{\circ} \mathrm{C} /$ decade, respectively. During the third data series, Chilas, Cherat, Drosh, and Gupis showed significant positive trends, at rates of $0.24,0.19,0.13$, and $0.27{ }^{\circ} \mathrm{C} /$ decade, respectively, while Risalpur and Skardu showed significant negative trends, of 0.21 and $0.17{ }^{\circ} \mathrm{C} / \mathrm{de}-$ cade, respectively. In the fourth series, Gilgit, Gupis, and Risalpur exhibited significant positive trends, at rates of $0.21,0.14$, and $0.29^{\circ} \mathrm{C} /$ decade, respectively, while Ushkore, Naltar, and Yasin revealed significant negative trends, of 0.5 , 0.24, and $0.8^{\circ} \mathrm{C} /$ decade (Fig. 9a).

We found that during the summer, $T_{\text {mean }}$ for Gupis, Drosh, Peshawar, Risalpur, Naltar, Yasin, and Ziarat showed downward trends at rates of $0.28,0.13,0.11,0.16,0.31,0.21$, and $0.12{ }^{\circ} \mathrm{C} /$ decade, respectively (Fig. 9d). During the autumn, 8 stations showed significant trends: Cherat, Kakul, Naltar, and Yasin exhibited negative trends at $0.71,0.78,0.78$, and $0.49{ }^{\circ} \mathrm{C} /$ decade, respectively, while Chitral, Gilgit, Peshawar, and Saidu Sharif showed positive trends at rates of $0.23,0.38,0.34$, and $0.21^{\circ} \mathrm{C} /$ decade, respectively, during the fourth series. During the spring, Ziarat and Khunjrab showed significant positive trends, at rates of 0.26 and $0.13{ }^{\circ} \mathrm{C} /$ decade, while Naltar and Yasin showed significant negative trends, of 0.16 and $0.31{ }^{\circ} \mathrm{C} /$ decade, respectively. 


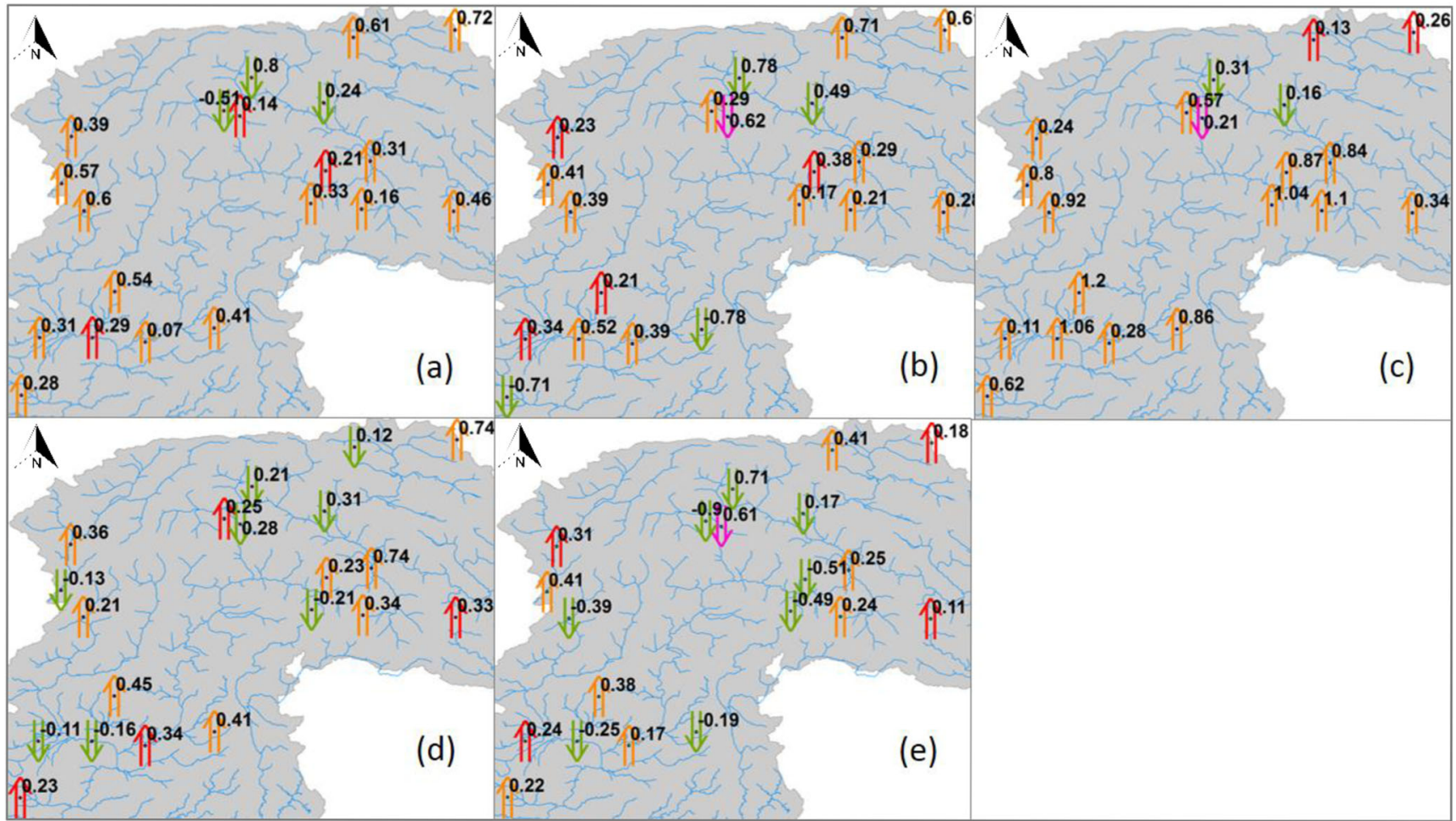

Fig. 9 Spatial distribution of trends for $T_{\text {mean }}$ temperature showing change in ${ }^{\circ} \mathrm{C}$ decade ${ }^{-1}$ during (1991-2013). a Annual. b Autumn. c Spring. d Summer. e Winter. (upward and downward arrow shows

positive and negative trends, yellow and pink (insignificant), red and green (significant trends at $\alpha=0.1$ )

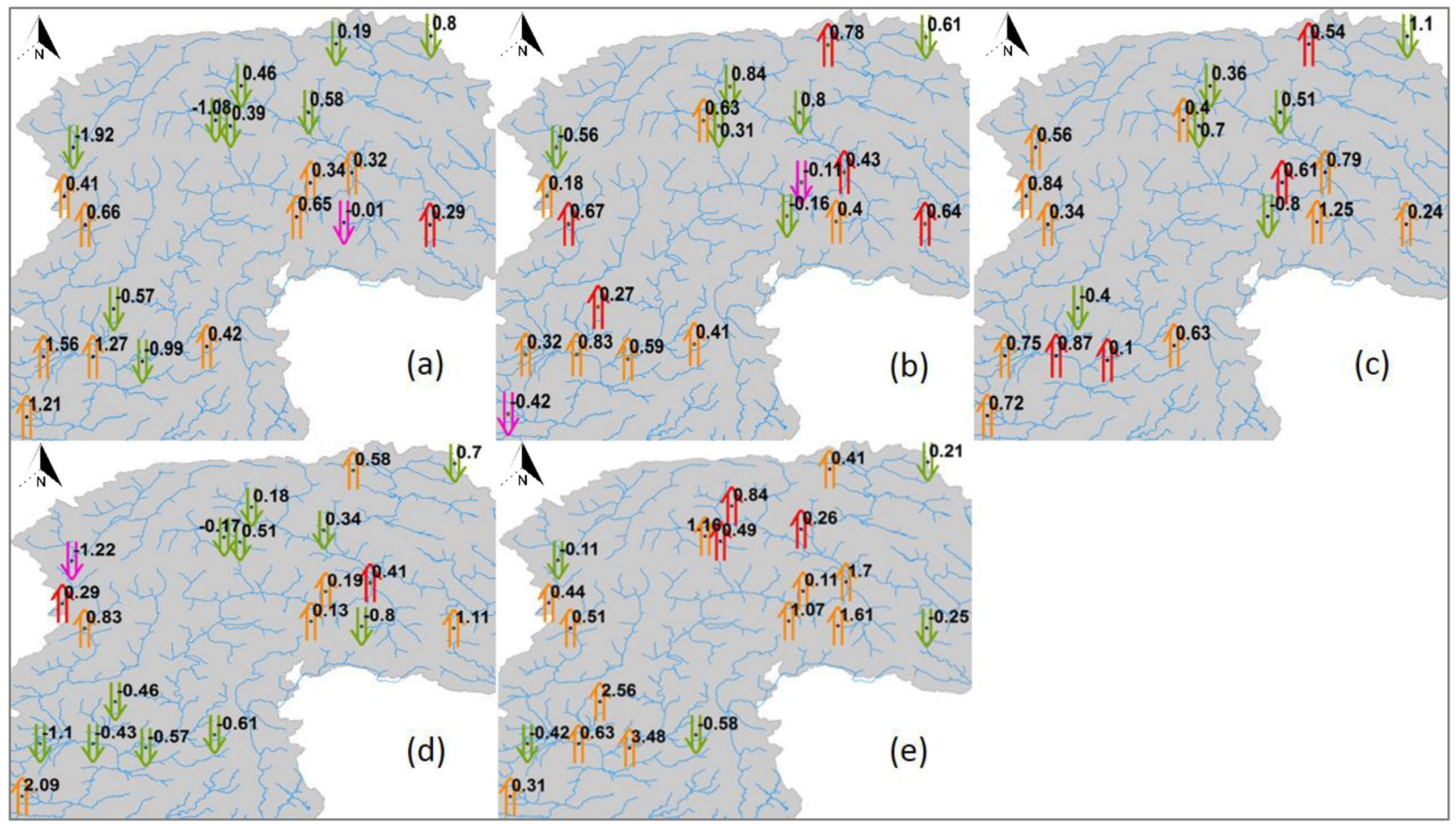

Fig. 10 Spatial distribution of trends for DTR temperature showing change in ${ }^{\circ} \mathrm{C}$ decade $^{-1}$ during (1991-2013). a Annual. b Autumn. c Spring. d Summer. e Winter. (upward and downward arrow shows positive and negative trends, yellow and pink (insignificant), red and green (significant trends at $\alpha=0.1$ ) 
During the winter, Chilas, Gilgit, Kakul, Risalpur, Ushkore, Naltar, and Yasin showed significant negative trends, at rates of $0.49,0.51,0.19,0.25,0.9,0.17$, and $0.71{ }^{\circ} \mathrm{C} /$ decade, whereas Chitral, Khunjrab, Peshawar, and Skardu exhibited significant positive trends, at rates of $0.9,0.18,0.21$, and $0.11{ }^{\circ} \mathrm{C} /$ decade, respectively. These results support the idea of cooling at Bunji and Gupis and show good agreement with Sheikh et al. (2009) of cooling in the mean annual temperatures at Gilgit, Gupis, and Bunji stations during the monsoon period (June-September), though generally we found dominant warming during the fourth time series.

\subsection{Trends in diurnal temperature range (DTR)}

Only four stations revealed significant trends during first data series: Gilgit and Peshawar showed upward trends, at rates of 0.37 and $0.19{ }^{\circ} \mathrm{C} /$ decade, while Chilas and Cherat exhibited downward trends, at 0.15 and $0.23{ }^{\circ} \mathrm{C} /$ decade, respectively. In the second series, three stations showed significant downward trends: Bunji, Chilas, and Peshawar, at rates of $0.11,0.15$, and $0.28{ }^{\circ} \mathrm{C} /$ decade, respectively. Only Risalpur showed a significant upward trend, at a rate of $0.29{ }^{\circ} \mathrm{C} /$ decade. In the third series, Bunji and Risalpur showed significant downward trends, at rates of 0.29 and $0.19{ }^{\circ} \mathrm{C} /$ decade, respectively. In the fourth series, Chitral, Gupis, Kohat, Khunjrab, Ushkore, Naltar, Saidu Sharif Yasin, and Ziarat showed significant downward trends, at rates of $1.92,0.39,0.99$, $0.8,1.08,0.58,0.57,0.46$, and $0.19{ }^{\circ} \mathrm{C} /$ decade, respectively. Only Skardu exhibited a significant upward trend, at a rate of $0.29{ }^{\circ} \mathrm{C} /$ decade. For the summer during the fourth data series (Fig. 10d), we found significant downward trends for Astore, Gupis, Kakul, Saidu Sharif, Peshawar, Risalpur, Kohat, Khunjrab, Naltar, Ushkore, and Yasin, at rates of $0.8,0.51,0.61,0.46$, $1.1,0.43,0.57,0.7,0.34,0.17$, and $0.18{ }^{\circ} \mathrm{C} /$ decade. Only Skardu showed a significant increasing trend, at a rate of $0.29{ }^{\circ} \mathrm{C} /$ decade. During the autumn for the fourth series, Chitral, Chilas, Gupis, Khunjrab, Naltar, and Yasin exhibited significant cooling at rates of $0.56,0.16,0.31,0.61,0.8$, and $0.84{ }^{\circ} \mathrm{C} /$ decade, with only Skardu and Ziarat showing significant warming of 0.64 and $0.78{ }^{\circ} \mathrm{C} /$ decade. During the spring, Chilas, Gupis, Khunjrab, Naltar, Saidu Sharif, and Yasin showed significant downward trends, at rates of 0.8 , $0.7,1.1,0.51,0.4$, and $0.36{ }^{\circ} \mathrm{C} / \mathrm{dec}$ de, while Gilgit and Ziarat showed significant upward trends of 0.61 and $0.54{ }^{\circ} \mathrm{C} /$ decade respectively. During the winter Chitral, Kakul, Khunjrab, Peshawar, and Skardu showed significant downward trends, of $0.11,0.58,0.21,0.42$, and $0.25{ }^{\circ} \mathrm{C} /$ decade, while Gupis, Naltar, and Yasin revealed significant upward trends of $0.49,0.26$, and $0.84{ }^{\circ} \mathrm{C} /$ decade (Fig. 10e).

\section{Discussion}

We observed the temporal changes over this region, which significantly exhibited a definite pattern of decreasing annual temperature during all data series, but most robustly within the fourth data series. Previous studies examined these stations within the UIB but were mostly restricted to low-altitude stations having a limited length of records. We present a comprehensive analysis based on updated accessible data of high- as well as low-altitude stations ranging from $900 \mathrm{~m}$ to 4500 m.a.s.l.

Our $T_{\max }$ trend analysis suggests cooling tendencies annually and seasonally. Predominantly, summer and winter cooling increased during all data series, notably the first and fourth, while for autumn and spring, most stations exhibited insignificant decreasing trends, particularly during the third and fourth data series. The daily mean temperature is used as a measuring tool for the assessment of climate change studies. However, complex inconsistencies of climate cannot be explained solely by mean temperature (Qu et al. 2014). Sun and Zhang (2006) reported that mean temperature trends are usually dictated by fluctuations in the daily maximum and minimum temperature. One would, therefore, expect that DTR can also be used as an indirect indicator of climate change (Karl et al. 2015). Previous studies (Karl et al. 1984, 1991, 1993) have briefly explained the role of DTR by reporting a steady decrease in the United States of America (USA), attributed to the reduction in daily temperature and stagnant daily maximum temperature. They additionally noted the role of cloud cover and land-use changes and concluded that DTR decreased during cloudy days. We find most of the stations exhibit significant trends of DTR at low- as well as high-altitude stations. Our findings are consistent with results of global DTR decrease (Jones et al. 1999) and decrease within northeast China, but in direct contrast to findings within the UIB (Fowler and Archer 2006) and over India (Yadav et al. 2004). We find significant warming at Astore and Bunji, in agreement with Hasson et al. (2015), who reported long-term warming at low-altitude stations, contrary to the trends at high altitude (1995-2012). We find a similar pattern of decreasing trends, except at Ziarat, which shows significant warming, at a rate of $0.3{ }^{\circ} \mathrm{C} / \mathrm{dec}$ ade, contrary to Hasson et al. 2015. The summer decreasing trends during the last two data series are dissimilar to the idea of DTR reducing worldwide and within northeast China. This is attributed to the stronger cooling effect in $T_{\max }$ and $T_{\min }$ in our study. The observed decreasing trends of DTR during the spring reflect more substantial cooling in $T_{\max }$ and $T_{\min }$ in the spring. When compared to the standard and adjacent regions, the UIB features some typical patterns of trends, though for different reasons. Archer and Fowler (2006) attributed the area-wide increase in DTR in the western Himalaya to atmospheric circulation. Our outcomes partially agree with the findings of Hasson et al. 2015 
who reported a substantial decrease in DTR during (19952012). They reported, overall, that high-altitude stations exhibit a less strong but robust pattern of yearly decrease in DTR compared to low-altitude locations.

We found a cooling trend for $T_{\max }$ in the autumn at Gilgit and Bunji during last two data series, which is consistent with Fowler and Archer 2006 and Hasson et al. 2015. During the summer, however, we observe steady warming trends at Astore and Bunji, which is inconsistent with these authors. We also find cooling tendencies during the spring and winter, consistent with Khattak et al. 2011 and Fowler and Archer 2006. Our results are inconsistent with the results discussed (warming or insignificant trends) by Hasson 2015.

We noted a stronger cooling effect during the summer in $T_{\max }$ and $T_{\min }$. This cooling effect becomes more active regarding its magnitude and the number of stations at which it appears during the fourth data series. A similar significant cooling effect is noted at high-altitude stations. Cook et al. (2003) reported the same cooling tendencies and attributed this phenomenon to the South Asian summer monsoon system over the Karakoram. These results support the idea of increasing cloud cover and wet days (Bocchiola and Diolaiuti 2013) and the extension of the monsoonal domain (Hasson et al. 2015). However, our results are only partially consistent with the findings of the studies mentioned above as we noted significant and constant warming at Astore, Bunji, and Saidu Sharif during the fourth data series. This is attributed to decreased monsoonal precipitation and a weaker impact of the Asian monsoon (Latif et al. 2016). We observed a significant increase in $T_{\max }$ and $T_{\min }$ during the autumn, including at high-altitude stations. These results do not agree with the findings of Khattak et al. (2011) and Hasson et al. (2015), who reported the highest warming during the winter and spring, respectively. Conversely, the maximum warming was observed during the autumn. We also observed similar warming trends at high-altitude stations, but they were statistically insignificant. These results are consistent with Hasson et al. (2015), who also found statistically significant dominating warming trends on an annual timescale at the five stations including Gilgit, which showed warming at a rate of $0.4{ }^{\circ} \mathrm{C} /$ decade. We also found significant cooling at Skardu, at $0.4{ }^{\circ} \mathrm{C} / \mathrm{dec}$ ade, as reported by the same authors. Our results are inconsistent with those of the IPCC (2013) of decreasing spring snow-cover extent in the Northern Hemisphere and worldwide. The warming pattern during the autumn at most of the stations is also inconsistent with decreasing snow cover regionally (Hasson et al. 2014; Tahir et al. 2011). However, our results are in phase with the findings of Mukhopadyay et al. (2014), who reported an insignificant increase in snow cover area during 2000-2010. The changes in cloud properties and cloud cover control shortwave and longwave radiation, maintaining the energy budget. Liu et al. (2009) reported decreasing cloud cover during daytime and increasing low-level clouds at night. Duan and Wu (2009) attributed this phenomenon to warming (increasing $T_{\min }$ ). We noted steady warming trends at Khunjrab and Naltar that might be associated with such occurrences. Muhammad and Tian (2016) reported a slight decrease in glacier area, but an increase in the debris cover of glaciers in the Karakoram. These results support the idea of mass loss attributed to warming over high-altitude regions reported by different authors. Such findings and assumptions require further detailed analysis based on field excursions and data collection.

\section{Conclusions}

We observed cooling and warming amplifications over the high mountains with significant and insignificant magnitudes appearing within different data periods and seasons during 1961-2013. The major outcomes of this study are summarized as follows

1. Temporal changes in $T_{\max }$ during the fourth data series seem more robust than the rest of the series over the entire UIB. We have noted a strong summer and winter cooling at low and high-altitude stations. The spatial distribution of trends revealed that the northern stations Bunji and Skardu showed significant cooling in the fourth series. Khunjrab, Naltar, southwestern stations (Drosh), and lower-reach catchments (Peshawar) have shown significant warming during the last two decades. $T_{\max }$ revealed cooling and warming during the second and third series, but autumn exhibited a robust cooling pattern during the fourth series. The spatial analysis confirmed that Skardu and Chilas showed cooling; foothill catchments (Cherat and Kakul) also exhibited cooling during 1961-2013, whereas Ziarat revealed a warming tendency annually and during the spring.

2. Autumn and summer $T_{\text {mean }}$ indicated warming, particularly during the third and fourth series. Ziarat and Khunjrab revealed robust warming, which is stronger during the spring, at rates of 0.26 and $0.13{ }^{\circ} \mathrm{C} /$ decade attributed to EDW. Warming of the climate may result in glacier mass loss, rendering an increased annual short-term glacier melt contribution to stream flows (Miller et al. 2012).

3. DTR revealed a complex behavior (insignificant) compared to other constraints in the UIB during the first three series, but summer DTR showed cooling at most stations. Khunjrab exhibited continued cooling throughout the season. The temperature will be rising more rapidly if the precipitation pattern continues decreasing at the same rates, thereby resulting in a stressful condition for water resources (Latif et al. 2016).

Contemporaneous investigation of 20 climatic stations temperature (summer cooling) yielded results partially supporting the Karakoram Anomaly (Hasson et al. 2015, Minora et al. 
2013, Hewitt 2005, Kääb et al. 2015) and increasing snow cover (Mukhopadyay et al. 2014), as we noted significant warming at high-elevation Khunjrab and Naltar. However, these results are inconsistent with EDW, since we find cooling at most of the high-altitude stations, particularly within Gilgit and Hunza Basins. Our results are unable to support the prevailing supposition of rapid melting or disappearing glaciers within the UIB (Karakoram) due to global warming. These results are partially consistent with EDW, since we find significant warming over Khunjrab and Naltar during the autumn and spring but cooling during the summer and winter. This analysis concludes that decreasing temperature dominates the UIB, both temporally and spatially, including some high-elevation stations. Nevertheless, these earliest outcomes need to be validated using additional data collected in the field and different variables indicating changing climate at high altitude.

Acknowledgments The authors gratefully acknowledge the Institute of Tibetan Plateau Research Chinese Academy of Sciences for postselection research services and funding this research. We are highly indebted to the Water and Power Development Authority Pakistan (WAPDA) for providing access to reliable data to work on and to publish valuable information. Likewise, the authors appreciate the anonymous reviewers for their excellent suggestions to improve this research article. We also appreciate the contribution of Dr. Szentimary Tamas for his precious time and sincere efforts to improve the results of the homogeneity analysis.

Funding Information This research was financed by the Chinese Academy of Sciences (XDB03030201), the CMA Special Fund for Scientific Research in the Public Interest (GYHY201406001), the National Natural Science Foundation of China (91337212, 41275010), and EU-FP7 projects of "CORE-CLIMAX” (313085).

Open Access This article is distributed under the terms of the Creative Commons Attribution 4.0 International License (http:// creativecommons.org/licenses/by/4.0/), which permits unrestricted use, distribution, and reproduction in any medium, provided you give appropriate credit to the original author(s) and the source, provide a link to the Creative Commons license, and indicate if changes were made.

\section{References}

Aguilar E, Auer I, Brunet M, Peterson TC, Wieringa J (2003) Guidelines on climate metadata and homogenization. World Meteorological Organization, WMO-TD No. 1186, WCDMP No. 53, Geneva, Switzerland, $\mathrm{p} 55$

Archer D (2003) Contrasting hydrological regimes in the upper Indus Basin. J Hydrol 274(1-4):198-210

Archer D, Fowler H (2004) Spatial and temporal variations in precipitation in the Upper Indus Basin, global teleconnections and hydrological implications. Hydrol Earth Sys Sci 8:47-61

Alexandersson H (1986) A homogeneity test applied to precipitation data. J Climatol 6:661-675. https://doi.org/10.1002/joc.3370060607

Ali G, Hasson S, Khan A (2009) Climate change: implications and adaptation of water. GCISC-RR-13. Global Change Impact Study Centre, Islamabad, Pakistan
Aziz O, Burn D (2006) Trends and variability in the hydrological regime of the Mackenzie River basin. J Hydrol 319:282-294

Bocchiola D, Diolaiuti G (2013) Recent (1980-2009) evidence of climate change in the upper Karakoram, Pakistan. Theor Appl Climatol 113: 611-641

Bolch T, Kulkarni A, Kaab A, Huggel C, Paul F, Cogley JG, Frey H, Kargel JS, Fujita K, Scheel M, Bajracharya S, Stoffel M (2012) The State and Fate of Himalayan Glaciers. Science 336 (6079):310-314

Bhutiyani M, Kale V, Pawar N (2007) Long-term trends in maximum, minimum and mean annual air temperatures across the northwestern Himalaya during the twentieth century. Clim Chang 85:159-177

Bradley R, Vuille M, Diaz H, Vergara W (2006) Threats to water supplies in the tropical Andes. Science 312:1755-1756

Caloiero T, Coscarelli R, Ferraric E, Mancinia M (2011) Trend detection of annual and seasonal rainfall in Calabria (southern Italy). Int $\mathbf{J}$ Climatol 31:44-56

Conrad V, Pollak LW (1950) Methods in climatology, 2nd edn. Harvard university press, Cambridge, Massachusetts

Cook ER, Krusic PJ, Jones PD (2003) Dendroclimatic signals in long tree-ring chronologies from the Himalayas of Nepal. Int J Climatol 23(7):707-732

Cheema MJM, Bastiaanssen WGM (2012) Local calibration of remotely sensed rainfall from the TRMM satellite for different periods and spatial scales in the Indus Basin. Int J Remote Sens 33:2603-2627

Costa AC, Soares A (2008) Identification of inhomogeneities in precipitation time series using stochastic simulation geostatistics for environmental applications. In: 275-282

Dahmen E, Hall M (1990) Screening of hydrological data. Tests for stationarity and relative consistency. ILR1 Publication, Wageningen No. 49

del Río S, Herrero L, Pinto-Gomes C, Penas A (2011) Spatial analysis of mean temperature trends in Spain over the period 1961-2006. Glob Planet Chang 78(1-2):65-75

Duan A, Wu G (2006) Change of cloud amount and the climate warming on the Tibetan Plateau. Geophys Res Lett 33:L22704

Duan A, Wu G (2009) Change of cloud amount and the climate warming on the Tibetan Plateau. Geophys Res Lett 33:L22704

Forsythe N, Fowler HJ, Blenkinsop S, Burton A, Kilsby CG, Archer DR, Harpham C, Hashmi MZ (2014) Application of a stochastic weather generator to assess climate change impacts in a semi-arid climate: The Upper Indus Basin. J Hydrol 517:1019-1034

Fowler HJ, Archer DR (2006) Conflicting Signals of Climatic Change in the Upper Indus Basin. Journal of Climate 19 (17):4276-4293

Gardelle J, Berthier E, Arnaud Y (2012) Slight mass gain of Karakoram glaciers in the early twenty-first century. Nat Geosci Letters 5:322325

Guttman NB (1998) Comparing the Palmer Drought Index and the Standardized Precipitation Index. J Amer Water Resources Assoc 34(1):113-121

Hewitt K (2005) The Karakoram anomaly? Glacier expansion and the elevation effect Karakoram Himalaya. Mt Res Dev 25:332-340

Haan CT (1977) Statistical methods in hydrology, the Iowa state Univ. Press, Ames

Hasson S, Böhner J, Lucarini V (2015) Prevailing climatic trends and runoff response from Hindukush-Karakoram-Himalaya, upper Indus basin. Earth Syst Dynam Discuss 6:579-653

Hasson S, Lucarini V, Khan M, Petitta M, Bolch T, Gioli G (2014) Early 21st century snow cover state over 5 the western river basins of the Indus River system. Hydrol Earth Syst Sci 18:4077-4100

Immerzeel W (2008) Historical trends and future predictions of climate variability in the Brahmaputra basin. International J Climat 28:243254

IPCC (2007) Climate change 2007: Synthesis report. Contribution of working groups I, II and III to the fourth assessment report of the intergovernmental panel on climate change. Core writing team. In: 
Pachauri RK, Reisinger A (eds) . Intergovernmental Panel on Climate Change (IPCC), Geneva, Switzerland

IPCC (2013) In: Stocker TF, Qin D, Plattner G-K, Tignor M, Allen SK, Boschung J, Nauels A, Xia Y, Bex V, Midgley PM (eds) Climate change 2013: the physical science basis. Contribution of working group $i$ to the fifth assessment report of the intergovernmental panel on climate change. Cambridge University Press, Cambridge, United Kingdom and New York, NY, USA 1535pp

Irrigation in Southern and Eastern Asia in Figures: Aquastat Survey, 2011 Jaagus J (2006) Climatic changes in Estonia during the second half of the 20th century in relationship with changes in large-scale atmospheric circulation. Theor Appl Climatol 83:77-88

Jarusková D (1994) Change-point detection in meteorological measurement. Mon Wea Rev 124:1535-1543

Jones PD, Moberg A (2003) Hemispheric and Large-Scale Surface Air Temperature Variations: An Extensive Revision and an Update to 2001. J Climate 16(2):206-223

Miller JD, Immerzeel WW, Rees G (2012) Climate change impacts on glacier hydrology and river discharge in the Hindu Kush-Himalayas. Mountain Research and Development 32(4):461-467

Karl TR, Kukla G, Gavin J (1984) Decreasing Diurnal Temperature Range in the United States and Canada from 1941 through 1980. J Clim Appl Meteorol 23(11):1489-1504

Karl TR, Kukla G, Razuvayev VN, Changery MJ, Quayle RG, Heim RR, Easterling DR, Fu CB (1991) Global warming: Evidence for asymmetric diurnal temperature change. Geophys Res Lett 18(12):22532256

Karl TR, Knight RW, Gallo KP, Peterson TC, Jones PD, Kukla G, Plummer N, Razuvayev V, Lindseay J, Charlson RJ (1993) A New Perspective on Recent Global Warming: Asymmetric Trends of Daily Maximum and Minimum Temperature. Bull Amer Meteor Soc 74(6): 1007-1023

Karl R, Arguez A, Huang B, Lawrimore JH, McMahon JR, Menne MJ, Thomas C (2015) Science 348:1469-1472

Khattak M, Babel S, Sharif M (2011) Hydro meteorological trends in the upper Indus River basin in Pakistan. Clim Res 46:103-119. https:// doi.org/10.3354/cr00957

Kääb A, Treichler D, Nuth C, Berthier E (2015) Brief communication: contending estimates of 2003-2008 glacier mass balance over the Pamir-Karakoram-Himalaya. Cryosphere 9(2):557-564

Khaliq M, Ourda T, Gachon P, Sushma L, St-Helaire A (2009) Identification of hydrological trends in presence of serial and cross correlation: a review of selected methods and their application to annual flow regime of Canadian rivers. J.Hydrol 368:117-130

Kumar S, Merwade V, Kam J, Thurner K (2009) Stream flow trends in Indiana: effects of long term persistence, precipitation and subsurface drains. J. Hydrol 374:171-183

Kulkarni A, Von Storch H (1999) Monte Carlo experiments on the effect of serial correlation on the Mann-Kendal test of trend. Meteorol Z 4: $82-85$

Kendall MG (1975) Rank correlation methods, 4th edn. Charles Griffin, London

Kääb A, Leinss S, Gilbert A, Bühler Y, Gascoin S, Evans SG, Bartelt P, Berthier E, Brun F, Chao W, Farinotti D, Gimbert F, Guo W, Huggel C, Kargel JS, Leonard GJ, Tian L, Treichler D, Yao T (2018) Massive collapse of two glaciers in western Tibet in 2016 after surge-like instability. Nat. Geo Sci 11:114-120. https://doi.org/10. 1038/s41561-017-0039-7

Kraaijenbrink PDA, Bierkens MFP, Lutz AF, Immerzeel WW (2017) Impact of a global temperature rise of 1.5 degrees Celsius on Asia's glaciers. Nature 549:257-260

Mann HB (1945) Nonparametric tests against trend. Econometrica 13(3): 245-259

Mavromatis T, Stathis D (2011) Response of the water balance in Greece to temperature and precipitation trends. Theor Appl Climatol 104: 13. https://doi.org/10.1007/s00704-010-0320-9
Minora U, Bocchiola D, D’Agata C, Maragno D, Mayer C, Lambrecht A, Mosconi B, Vuillermoz E, Senese A, Compostella C, Smiraglia C, Diolaiuti G (2013) 2001-2010 glacier changes in the Central Karakoram National Park: a contribution to evaluate the magnitude and rate of the "Karakoram anomaly". The Cryosphere Discussions 7 (3):2891-2941

Minora U, Bocchiola D, D'Agata C, Maragno D, Mayer C, Lambrecht A, Diolaiuti GA (2016) Glacier area stability in the Central Karakoram National Park (Pakistan) in 2001-2010: the "Karakoram Anomaly" in the spotlight. Prog Phys Geogr 40:629-660. https://doi.org/10. 1177/0309133316643926

Muhammad S, Tian L (2016) Changes in the ablation zones of glaciers in the western Himalaya and the Karakoram between 1972 and 2015. Remote Sens Environ 187:505-512

Mukhopadhyay B, Khan A (2014) Rising river flows and glacial mass balance in central Karakoram. J Hydrol 513:192-203

Novotny E, Stefan H (2007) Stream flow in Minnesota: indicator of climate change. J. Hydrol 334:319-333

Oguntunde PG, Abiodun BJ, Lischeid G (2011) Rainfall trends in Nigeria, 1901-2000. J Hydrol 411(3-4):207-218

Lutz AF, Immerzeel WW, Kraaijenbrink PDA, Shrestha AB, Bierkens MFP (2016) Climate change impacts on the Upper Indus hydrology: sources, shifts and extremes. PLoS One 11(11):e0165630

Latif Y, Yaoming M, Yaseen M (2016) Spatial analysis of precipitation time series over Upper Indus Basin. Theor Appl Climato. https://doi. org/10.1007/s00704-016-2007-3

Liu X, Cheng Z, Yan L, Yin Z (2009) Elevation dependency of recent and future minimum surface air temperature trends in the Tibetan Plateau and its surroundings. Glob Planet Change 68:164-174

Pellicciotti F, Buergi C, Immerzeel WW, Konz M, Shrestha AB, Challenges and Uncertainties in Hydrological Modeling of Remote Hindu Kush-Karakoram-Himalayan (HKH) Basins (2012) Suggestions for calibration strategies. Mt Res Dev 32(1):39-50

Pepin N, Seidel D (2005) A global comparison of surface and free-air temperatures at high elevations. J Geophys Res 110:D03104. https:// doi.org/10.1029/2004JD005047

Pepin NC, Bradley RS, Diaz HF, Baraer M, Caceres EB, Forsythe N, Fowler H, Greenwood G, Hashmi MZ, Liu XD, Miller JR, Ning L, Ohmura A, Palazzi E, Rangwala I, Schöner W, Severskiy I, Shahgedanova M, Wang MB, Williamson SN, Yang DQ (2015) Elevation-dependent warming in mountain regions of the world. Nat Clim Chang 5:424-430. https://doi.org/10.1038/nclimate2563

Pfeffer W T, Arendt A, Bliss A, Bolch T, Cogley JG, Gardner A S, Hagen JO, Hock R, Kaser G, Kienholz C, Miles ES, Moholdt G, Mölg N, Paul F, Radić V, Rastner P, Raup BH, Rich J, Sharp MJ (2014) The Randolph Glacier Inventory: a globally complete inventory of glaciers. Journal of Glaciology 60 (221):537-552

Qu X, Hall A, Klein SA, Caldwell PM (2014) On the spread of changes in marine low cloud cover in climate model simulations of the 21st century. Clim Dyn 42:2603-2626. https://doi.org/10.1007/s00382013-1945-z

Rangwala I, Miller JR, Russell GL, Xu M (2010) Using a global climate model to evaluate the influences of water vapor, snow cover and atmospheric aerosol on warming in the Tibetan Plateau during the twenty-first century. Clim Dyn 34(6):859-872. https://doi.org/10. 1007/s00382-009-0564-1

Rangwala I, Sinsky E, Miller JR (2013) Amplified warming projections for high altitude regions of the Northern Hemisphere mid-latitudes from CMIP5 models. Environ Res Lett 8:024040. https://doi.org/10. 1088/1748-9326/8/2/024040

Rio D, Penas A, Fraile R (2005) Analysis of recent climatic variations in Castile and Leon (Spain). Atmos Res 73:69-85

Sen P (1968) Estimates of regression coefficients based on Kendall s tau. J Am Stat Assoc 63:1379-1389

Sheikh M, Manzoor N, Adnan M, Ashraf J, Khan A (2009) Climate profile and past climate changes in Pakistan, GCISC-RR-01, 
Global Change Impact Studies Centre (GCISC), Islamabad, Pakistan, 2009

Shrestha A, Devkota L (2010) Climate change in the Eastern Himalayas: observed trends and model projections; Climate change impact and vulnerability in the Eastern Himalayas - Technical report 1.Kathmandu: ICIMOD

Sun D, Zhang T (2006) A regulatory effect of ENSO on the time-mean thermal stratification of the equatorial upper ocean. Geophys Res Lett 33:L07710. https://doi.org/10.1029/2005GL025296

Szentimrey T PY - 2008/01/01 SP - 123 EP - 130 T1 - Development of MASH homogenization procedure for daily data JO - Proceedings of the Fifth Seminar for Homogenization and Quality Control in Climatological Databases

Tabari H, Hosseinzadeh Talaee P (2011) Recent trends of mean maximum and minimum air temperatures in the western half of Iran. Meteorol Atmos Phys 111(3-4):121-131

Tabari H, Talaee PH, Ezani A, Some'e B (2012) Shift changes and monotonic trends in auto correlated temperature series over Iran. Theor Appl Climatol 109:95-108. https://doi.org/10.1007/s00704-0110568-8

Tad Pfeffer W, Arendt AA, Bliss A, Bolch T, Graham Cogley J, Gardner AS, Hagen J-O, Hock R, Kaser G, Kienholz C, Miles ES, Moholdt G, Mölg N, Paul F, Radić V, astner P, Raup BH, Rich J, Sharp MJ (2014) The Randolph Glacier Inventory: a globally complete inventory of glaciers. J Glaciol 60(221):537-552

Tahir AA, Chevallier P, Arnaud Y, Neppel L, Ahmad B (2011) Modeling snowmelt-runoff under climate scenarios in the Hunza River basin, Karakoram Range, Northern Pakistan. J Hydrol 409(1-2):104-117

Tian L, Yao T, GAO Y, Thompson L, Ellen M, Sher M, ZONG J, Wang C, JIN S, LI Z (2017a) Two glaciers collapse in western Tibet. J Glaciol 63:194-197

Tian 1, Yao t, Gao y, Thompson 1, Mosley-Thompson e, Muhammad S, Li Z (2017b) Two glaciers collapse in western Tibet. J Glaciol 63(237): 194-197. https://doi.org/10.1017/jog.2016.122
Von Storch H, Navarra A (1999) Analysis of Climate Variability: Applications of Statistical Rechniques. Springer Verlag, Berlin

World Meteorological Organization (1997) Guidance on automatic weather systems and their implementation. Instruments and observing methods report no. 65, WMO/TD-no. 862, Geneva

Wang B, Bao Q, Hoskins BJ, Wu G, Liy YM (2008) Tibetan plateau warming and precipitation changes in East Asia. Geophys Res Lett 35. https://doi.org/10.1029/2008GL034330

World Meteorological Organization (1983) Guide to Climatological Practices. Second edition, Part I, Chapter 2, WMO-No. 100, Geneva (updates available at: http://www.wmo.ch/pages/prog/wcp/ $\mathrm{ccl} /$ guide/guide_climat_practices.html)

World Meteorological Organization (2003) Algorithms Used in Automatic Weather Stations: Evaluation of Questionnaire (M.D. Gifford). Instruments and Observing Methods Report No. 78, WMO/TD-No. 1160, Geneva

WMO CBS Expert Team on Requirements For Data From Automatic Weather Stations -3rd Session, Geneva, 28 June - 2 July 2004

Yadav RR, Park W-K, Singh J, Dubey B (2004) Do the western Himalayas defy global warming? Geophys Res Lett 31(17). https://doi.org/10.1029/2004GL020201

Yue S, Pilon P, Cavadias G (2002) Power of the Mann-Kendall and Spearman's rho tests for detecting monotonic trends in hydrological series. J Hydrol 259:254-271

Yue S, Wang C (2004) The Mann-Kendall test modified by effective sample size to detect trend in serially correlated hydrological series. Water Resour Manag 18:201-218

Yao T, Thompson L, Mosbrugger V, Zhang F, Ma Y, Luo T, Fayziev R (2012) Third pole environment (TPE). Environ Dev 3:52-64. https://doi.org/10.1016/j.envdev.2012.04.002

Publisher's note Springer Nature remains neutral with regard to jurisdictional claims in published maps and institutional affiliations. 